This item was submitted to Loughborough's Research Repository by the author.

Items in Figshare are protected by copyright, with all rights reserved, unless otherwise indicated.

\title{
Electrospinning of poly(lactic acid): Theoretical approach for the solvent selection to produce defect-free electrospun nanofibres
}

PLEASE CITE THE PUBLISHED VERSION

http://dx.doi.org/10.1002/polb.24042

PUBLISHER

(c) Wiley

VERSION

AM (Accepted Manuscript)

\section{PUBLISHER STATEMENT}

This work is made available according to the conditions of the Creative Commons Attribution-NonCommercialNoDerivatives 4.0 International (CC BY-NC-ND 4.0) licence. Full details of this licence are available at: https://creativecommons.org/licenses/by-nc-nd/4.0/

\section{LICENCE}

CC BY-NC-ND 4.0

\section{REPOSITORY RECORD}

Casasola, Raffaella, Noreen L. Thomas, and Stella Georgiadou. 2016. "Electrospinning of Poly(lactic Acid): Theoretical Approach for the Solvent Selection to Produce Defect-free Electrospun Nanofibres”. figshare. https://hdl.handle.net/2134/20764. 


\title{
Electrospinning of Poly (lactic acid): Theoretical Approach for the Solvent Selection to Produce Defect-free Nanofibres
}

\author{
R. Casasola ${ }^{a}$, N. L. Thomas ${ }^{b}$, S. Georgiadou ${ }^{a^{*}}$ \\ ${ }^{a}$ Department of Chemical Engineering, Loughborough University, Loughborough, \\ Leicestershire, LE11 3TU, UK \\ ${ }^{b}$ Materials Department, Loughborough University, Loughborough, Leicestershire, LE11 \\ 3TU, UK \\ * Corresponding author. Tel: +44 (0)1509 222521 \\ E-mail address: S.Georgiadou@lboro.ac.uk
}

\begin{abstract}
In this study an integrated methodology is proposed for the selection of solvent systems to produce electrospinnable solutions that form defect-free poly (lactic acid) fibres with narrow diameter distributions. The solvent systems are chosen using a thermodynamic approach, combined with electrical and rheological property criteria. More specifically, the three step methodology includes 1) initial choice of solvent by solubility evaluation to meet thermodynamic criteria, 2) electrical properties i.e. conductivity and dielectric constant adjustment by using solvent mixtures to meet electrical property criteria, and 3) critical entanglement concentration $\left(\mathrm{C}_{\mathrm{e}}\right)$ determination by viscosity measurements, supported by elastic and plastic moduli measurements, followed by concentration adjustment to meet rheological criteria. All three criteria need to be met to ensure defect-free nanofibre morphology. The methodology is demonstrated using poly (lactic acid) solutions that were characterised in terms of thermodynamic properties, conductivity, surface tension and viscosity measurements. These data were analysed and related to the nanofibre morphology and diameter as determined from scanning electron microscopy (SEM). Measurements of the elastic (G') and the plastic (G') moduli of PLA solutions showed a sharp increase of G' at the chain entanglement concentration.
\end{abstract}

Keywords: electrospinning, poly(lactic acid), solubility parameter. 


\section{Introduction}

The choice of a suitable solvent system for a given polymer and the polymer concentration are the essential factors that determine the electrical and rheological properties of a polymer solution to ensure successful production of continuous nanofibres $(1,2)$. The interactions between solvent and polymer have been found to be important in determining the solution electrospinnability (3). Hence, the understanding of polymer dissolution in a solvent has a key role in electrospinning, because it allows optimization of the processing conditions. The chemical structure of a specific polymer determines its solubility in various solvents because a specific polymer will dissolve in solvents with similar solubility parameters to its own $(2,4,5)$. As a first step in choosing a suitable solvent system, the Flory-Huggins chi parameter $[\chi]$ has been used to indicate the compatibility of solvent and polymer (6,7). It uses the Hildebrand solubility parameter of solvent $\left(\delta_{\mathrm{S}}\right)$ and polymer $\left(\delta_{\mathrm{P}}\right)$, as shown in Equation 1 $(1,5,8,9)$, where $M_{s}$ is the molecular weight of the solvent $(\mathrm{g} / \mathrm{mol}), \mathrm{R}$ the universal gas constant $\left(\mathrm{MPa} \cdot \mathrm{cm}^{3} \cdot \mathrm{K}^{-1} \cdot \mathrm{mol}^{-1}\right)$, T the absolute temperature $(\mathrm{K})$, and $\rho_{\mathrm{s}}$ is the density of the solvent $\left(\mathrm{g} / \mathrm{cm}^{3}\right)$, the value 0.34 represents a lattice parameter.

$$
[\chi]=\left(\delta_{S}-\delta_{P}\right)^{2} \frac{M_{S}}{R T \rho_{S}}+0.34
$$

Equation 1

If $\chi$ is lower than 0.5 then there are favourable solvent-polymer interactions, whereas if $\chi$ is greater than 0.5 then polymer-polymer self-interactions are favoured, and the polymer chain coils will contract $(1,8,10)$. The Flory-Huggins parameter is a good indicator of how strong are the interactions between polymer chains and the solvent molecules. However it has been shown that this is not a general rule to predict polymer solubility since the secondary forces are not individually compared. For example Pattamaprom et al (8) dissolved poly styrene in dimethylformamide and nitrobenzene at all concentrations (10, 20, and 30\% w/v), despite the fact the $\chi$ parameter was much higher than 0.5. Moreover the Flory-Huggins parameter is a temperature-dependent quantity and also concentration-dependent over a wide range of polymer concentration (9).

Hansen (10) broke down the total solubility parameter into three components, $\delta_{\mathrm{D}}, \delta_{\mathrm{P}}, \delta_{\mathrm{H}}$, representing the dispersive (nonpolar), polar and hydrogen bond interactions. Using a threedimensional model to plot polymer solubility, Hansen showed that a sphere with radius $\mathrm{R}_{\mathrm{AO}}$, known as the interaction radius, could be formed for each polymer. Equation 2 represents the distance between the polymer and solvent, called $\mathrm{R}_{\mathrm{A}}$, which is the measure of how alike they are.

$$
R_{A}^{2}=4\left(\delta_{D, p}-\delta_{D, S}\right)^{2}+\left(\delta_{P, p}-\delta_{P, S}\right)^{2}+\left(\delta_{H, p}-\delta_{H, S}\right)^{2}
$$


The ratio $R_{A} / R_{A O}$ represents the Relative Energy Difference (RED). If its value is lower than 1 , this indicates that the liquid is a solvent for the polymer, whereas higher values indicate non-solvents (11).

The second step of solvent selection is to meet the electrical property criteria. On increasing the solution conductivity by addition of a solvent with higher dielectric constant $(\varepsilon)$, more charges are created on the jet surface which enhances the stability of the charged jet facilitating the formation of defect-free fibres (12-15). The dielectric constant reflects the polarity of the molecules (3). The higher the dielectric constant of a solvent, the more polar it is. High dielectric constant can help the jet flow getting a strong Coulomb repulsion force to overcome the surface tension. Generally non polar solvents have $\varepsilon$ lower than 5 (such as chloroform and benzene), while polar solvents have $\varepsilon$ higher than 20 (acetone, dimethylformamide, dimethyl sulfoxide, acetonitrile, methanol). 'Borderline' solvents with $\varepsilon$ between 5 and 20 are for example dichloromethane and tetrahydrofuran (16). The addition of DMF to poly(vinyl chloride) (PVC) solution in tetrahydrofuran (THF) enhanced the electrospinning of the PVC solution (14). Although dimethylformamide (DMF) is not a good solvent for PVC its addition caused the increase of the solution conductivity, and hence defect-free nanofibres with narrow diameter distribution were produced due to the higher dielectric constant of DMF (36.7) compared with that of THF (7.6). Similar findings were obtained by Hsu and Shivkumar for PCL solutions (17). Therefore the second electrical property criteria could be met by using solvent mixtures with a solvent of high dielectric constant.

After solvent selection, the next challenge for effective electrospinning is the optimization of the polymer concentration (18-20). Nanofibres can be produced within a specific range of polymer concentration that depends on the type of polymer and polymer-solvent interactions. Polymer concentration and molecular weight $\left(\mathrm{M}_{\mathrm{w}}\right)$ are the parameters that most affect nanofibre production because they determine the extent of chain entanglement in solution. If the molecular weight $\mathrm{M}_{\mathrm{w}}$ is fixed, the number of entanglements increases with the polymer volume fraction (21-23). The concentration at which significant overlap of the polymer chains occurs and so an entangled network is formed, is called the entanglement concentration, $\mathrm{C}_{\mathrm{e}}(24,25)$. The effect of concentration and thermodynamic interaction on the viscoelastic properties of polymer solutions was studied (26-28). Shear viscosity measurements have shown that for a linear polymer in a good solvent, the viscosity $(\eta)$ is proportional to $C^{1.25}$ in the unentangled regime while $\eta \sim C^{4.25-4.5}$ in the entangled regime (28). A number of researchers investigated the effect of polymer concentration (C) on shear viscosity $(\eta)$ and the relationship with the electrospun nanofibre morphology $(25,29-32)$. It was shown that while at concentration lower than $C_{e}$ the polymeric jet breaks into droplets and no nanofibres are collected (6), at $\mathrm{C}>\mathrm{C}_{\mathrm{e}}$ first beaded nanofibres are produced and then on further increasing the concentration, approximately when $\mathrm{C}$ is 2 or 2.5 times $\mathrm{C}_{\mathrm{e}}$, defectfree nanofibres are formed. 
A semi empirical approach has been proposed by Shenoy et al (33) to predict the polymer concentration that will successfully produce electrospun nanofibres. The number of entanglements in solution was defined as the ratio between the polymer molecular weight $\left(\mathrm{M}_{\mathrm{w}}\right)$ and the solution entanglement molecular weight $\left(\mathrm{M}_{\mathrm{e}}\right)_{\text {solution }}$ as shown in Equation 3. $\mathrm{M}_{\mathrm{e}}$ and $\emptyset_{p}$ are the entanglement molecular weight of the polymer and the polymer volume fraction, respectively.

$$
\left(n_{e}\right)_{\text {solution }}=\frac{M_{w}}{M_{e_{\text {solution }}}}=\frac{M_{w} \emptyset_{p}}{M_{e}}
$$

Equation 3

The semi empirical entanglements analysis was applied to several polymer-solvent systems. The experimental value of polymer concentration used to produce beaded nanofibre and then defect-free nanofibres was compared with the predicted value of concentration calculated from Equation 3. The authors stated that the fibre initiation occurs when $\left(n_{e}\right)_{\text {solution }} \sim 2$, while defect-free nanofibres are collected when $\left(n_{e}\right)_{\text {solution }}$ is approximately 3.5. This equation was shown to be valid in a number of polymer-solvent systems. However the effect of the solvent quality in this equation is not considered.

Although PLA is commonly used for electrospinning because of its use in many applications (34-37), there are very few papers that have systematically investigated the effect of the solvent type and polymer concentration on the morphology of PLLA nanofibres (38-40). Chloroform (CHL) and a mixture of dichloromethane and dimethylformamide (DCM/DMF) were used by Ren et al (38) to dissolve PLLA. The authors observed jet splitting using the solvent mixture, whereas there was no jet splitting using only chloroform due to its low boiling point and therefore thicker fibres were collected. In a previous paper (41) the current authors reported the effect of different solvent systems on nanofibre production and morphology of poly(lactic acid) (PLA). Of all the solvent systems used acetone/dimethylformamide (AC/DMF) gave the highest fibre productivity and finest, defectfree nanofibres. Viscosity measurements showed that the entanglement concentration, $C_{e}$, was in good agreement with the morphological analysis of the nanofibres produced. Moreover the elastic (G') modulus showed a sudden increase at the chain entanglement concentration.

The aim of this study is to provide a theoretical approach for selection of a solvent or a mixture of solvents to ensure the preparation of poly lactic acid electrospinnable solutions and the collection of uniform defect-free nanofibres with a narrow diameter distribution. The choice of solvent (or mixture of solvents) is made using a thermodynamic criterion, combined with electrical property (dielectric constant and solution conductivity) criterion. The entanglement concentration $\left(\mathrm{C}_{\mathrm{e}}\right)$ is determined by viscosity measurements that can be confirmed by elastic and plastic moduli measurements. The optimum polymer concentration 
can then be selected. The theoretical approach proposed here could be used for other polymers.

\section{Materials and methods}

\subsection{Materials}

Poly (lactic acid) was obtained from Nature Works LLC (PLA 4060D, 100kDa, PD 2.1). Acetone (AC), dimethylformamide (DMF), chloroform (CHL), 1,4-dioxane (DX) were supplied by Fischer Scientific and used without further purification. Table 1 shows some chemical-physical properties of the selected solvents.

Table 1. Properties of the solvents used in this study (BP is the boiling point, $\eta$ is the viscosity at $25^{\circ} \mathrm{C}, \varepsilon$ is the dielectric constant at $20^{\circ} \mathrm{C}, \sigma$ is the surface tension at $20^{\circ} \mathrm{C}$ ) taken from (42). $\delta$ is the Hildebrand solubility parameter (43).

\begin{tabular}{|l|c|c|c|c|c|c|}
\hline Solvent & Type & $\begin{array}{c}\text { BP } \\
\left({ }^{\mathbf{C}} \mathbf{C}\right)\end{array}$ & $\begin{array}{c}\boldsymbol{\eta} \\
(\mathbf{m P a} \cdot \mathbf{s})\end{array}$ & $\boldsymbol{\varepsilon}$ & $\begin{array}{c}\mathbf{\sigma} \\
(\mathbf{m N} / \mathbf{m})\end{array}$ & $\begin{array}{c}\mathbf{\delta} \\
\left(\mathbf{M P a}^{\mathbf{1} / 2}\right)\end{array}$ \\
\hline Acetone - AC & Polar & 56 & 0.308 & 20.6 & 23.3 & 20.2 \\
\hline Dimethylformamide - DMF & Polar & 153 & 0.920 & 36.7 & 35.0 & 24.8 \\
\hline 1,4-Dioxane - DX & Non-polar & 101 & 1.177 & 2.21 & 40.0 & 20.5 \\
\hline Chloroform - CHL & Non-polar & 61 & 0.563 & 4.80 & 27.2 & 19.0 \\
\hline
\end{tabular}

\subsection{Preparation of PLA solutions}

The polymer solutions for electrospinning were prepared by dissolving a pre-weighed amount of PLA in a known volume of AC, DMF, DX or CHL. The polymer was also dissolved in a mixture of AC/DMF, CHL/DMF and DX/DMF at a ratio of 50/50 v/v. All solutions were prepared in a glass bottle, and magnetically stirred at room temperature $\left(20-22^{\circ} \mathrm{C}\right)$ for about 4 hours, until complete dissolution of the polymer. The polymer concentration was varied from 3 to $20 \% \mathrm{w} / \mathrm{v}$ to investigate the effect on both solution viscosity and nanofibre morphology.

\subsection{Characterisation of PLA solutions}

The rheological properties of the PLA solutions were measured with a HAAKE VT550 rheometer equipped with a cone-plate measuring system (cone radius $40 \mathrm{~mm}$, cone angle 1.59 degrees, truncation $56 \mu \mathrm{m})$ at constant temperature $\left(25^{\circ} \mathrm{C}\right)$. A rotational test was used to 
determine the shear solution viscosity as a function of shear rate ranged from 0.1 to $1000 \mathrm{~s}^{-1}$. The viscosity values were taken at a shear rate of $10 \mathrm{~s}^{-1}$.

An oscillatory test was used to define the dynamic moduli, storage (elastic-G') and loss (plastic-G') moduli. The test was performed at a shear stress of $0.5 \mathrm{~Pa}$ between frequencies of 0.1 and $100 \mathrm{~Hz}$. The results of G' and G', were taken at a frequency of $1 \mathrm{~Hz}$. All measurements were repeated three times for each solution.

The surface tension of the PLA solutions was measured using an interfacial tension meter (Kruss, Model DSA100). For each solution, several measurements were taken and an average value was calculated. The electrical conductivity of the polymer solutions was determined using a conductivity meter (Jenway Model 470) with a cell constant $\mathrm{K}=1.07$ and accuracy of $\pm 0.5 \%$.

\subsection{Electrospinning process}

A horizontal electrospinning setup was used. A 20-ml plastic syringe (Luer lock syringe, Sigma Aldrich) and a pump system (PHD ULTRA ${ }^{\mathrm{TM}}$, Harvard Apparatus) were used to feed a constant polymeric solution $(1.0 \mathrm{ml} / \mathrm{h})$ through the needle. An electric field of $20 \mathrm{kV}$ between a collector and a needle was generated using a high voltage power supply. The syringe containing the polymeric solution was connected to the needle ( $20 \mathrm{G}$, inner diameter of $0.60 \mathrm{~mm}$ ) through a polyethylene capillary tube. A rectangular copper plate covered with aluminium foil was employed as collector, and located $15 \mathrm{~cm}$ from the needle tip for the deposition of nanofibres. During the electrospinning experiments the temperature registered between 20 and $23^{\circ} \mathrm{C}$, and the relative humidity was about $35 \%$. Three nanofibre samples were prepared from each solution.

\subsection{Electrospun fibre analysis}

After electrospinning each sample was firstly coated using a gold/palladium sputter coater for 2 minutes (SC7640, Emitech). Subsequently field emission scanning electron microscopy (FEG-SEM, LEO 1530VP) with an accelerating voltage of $5.0 \mathrm{kV}$ was used to observe the fibre morphology of the electrospun PLA membranes, and investigate the effect of the polymer concentration. Several images were taken for each sample. The diameter of PLA nanofibres was measured using image software (AxioVision Rel 4.8). 150 measurements for each sample were made to determine the mean nanofibre diameter. 


\section{Results and discussion}

To combine thermodynamic, electrical and rheological property criteria in an integrated solvent selection methodology, some aspects of the polymer/ solvent system interactions need to be further clarified or investigated. In the following paragraphs the solubility in terms of Flory Huggins and RED parameters, the relationship between polymer concentration and viscosity, and G' and G', in different solvents and the electrical properties are discussed.

\subsection{Solubility evaluation by Flory-Huggins parameter and RED value}

For all solvent systems used in this work and the previous work (41), the Flory-Huggins parameter $\chi$ was calculated using Equation 1 , with $\mathrm{R}$ of $8.314 \mathrm{MPa} \cdot \mathrm{cm}^{3} \cdot \mathrm{K}^{-1} \cdot \mathrm{mol}^{-1}$, and $\mathrm{T}$ $283.15 \mathrm{~K}$. The results are reported in Table 2 . The solubility parameter $\delta_{\mathrm{p}}$ used for PLA was calculated from the average of values found in the literature (44). The value calculated was $20.18 \mathrm{MPa}^{1 / 2}$.

Table 2. Molecular weight $\left(\mathrm{M}_{\mathrm{w}}\right)$ and density $(\rho)$ were taken from (45). Hansen solubility parameters of solvents $\left(\delta_{\mathrm{t}} \delta_{\mathrm{p}} \delta_{\mathrm{h}}\right)$ were taken from (43).

\begin{tabular}{|l|c|c|c|c|c|c|c|c|}
\hline & AC & DMF & DX & CHL & AC/DMF & DX/DMF & CHL/DMF & PLA \\
\hline$\delta_{\mathrm{t}}=\left(\delta_{\mathrm{d}}{ }^{2}+\delta_{\mathrm{p}}{ }^{2}+\delta_{\mathrm{h}}{ }^{2}\right)^{1 / 2}$ & 19.94 & 24.86 & 20.47 & 18.95 & 22.40 & 22.67 & 21.90 & 20.18 \\
\hline$\delta_{\mathrm{d}}$ dispersion $(\mathrm{MPa})^{1 / 2}$ & 15.50 & 17.40 & 19.00 & 17.80 & $/$ & $/$ & $/$ & 17.65 \\
\hline$\delta_{\mathrm{p}}$ polar $(\mathrm{MPa})^{1 / 2}$ & 10.40 & 13.70 & 1.80 & 3.10 & $/$ & $/$ & $/$ & 8.00 \\
\hline$\delta_{\mathrm{h}}{\text { hydrogen }(\mathrm{MPa})^{1 / 2}}^{1 / 2}$ & 7.00 & 11.30 & 7.40 & 5.70 & $/$ & $/$ & $/$ & 5.28 \\
\hline Density $\left(\mathrm{g} / \mathrm{cm}^{3}\right)$ & 0.791 & 0.948 & 1.033 & 1.483 & 0.869 & 0.990 & 0.823 & 1.24 \\
\hline $\mathrm{M}_{\mathrm{w}}(\mathrm{g} / \mathrm{mol})$ & 58 & 73 & 88 & 119 & $/$ & $/$ & $/$ & 100000 \\
\hline $\boldsymbol{\chi}$ & $\mathbf{0 . 3 4}$ & $\mathbf{1 . 0 3}$ & $\mathbf{0 . 3 4}$ & $\mathbf{0 . 3 9}$ & $\mathbf{0 . 4 9}$ & $\mathbf{0 . 5 5}$ & $\mathbf{0 . 4 4}$ & $/$ \\
\hline
\end{tabular}

While a $\chi$ value lower than 0.5 was obtained using $\mathrm{AC}, \mathrm{CHL}$ and $\mathrm{DX}$, a higher value was calculated for DMF. This means that AC, CHL, DX are good solvents for PLA and allow the polymer chains to expand in solution, while the value of $\chi$ (PLA-DMF) of 1.03 represents poor interactions between the two components. Molar volume $\left(\mathrm{V}_{\mathrm{m}}\right)$ and solubility parameter $\left(\delta_{\mathrm{t}}\right)$ of the solvent mixture AC/DMF, DX/DMF and CHL/DMF were calculated considering the volume fraction of the two components (50:50), and hence the Flory-Huggins chi parameter $\chi$ was determined. A $\chi$ value lower than 0.5 was calculated for AC/DMF and CHL/DMF, whereas a slightly higher value was calculated for DX/DMF. However, all solvents were able to dissolve PLA, and homogeneous solutions were formed at all concentrations used. 
The next step was the determination of the RED value $\left(\mathrm{R}_{\mathrm{A}} / \mathrm{R}_{\mathrm{AO}}\right)$ for all solvents. The Hansen solubility parameters $\left(\delta_{\mathrm{D}}, \delta_{\mathrm{P}}, \delta_{\mathrm{H}}\right)$ of PLA are reported in Table 2 , and $\mathrm{R}_{\mathrm{AO}}$ is $11.26 \mathrm{MPa}^{1 / 2}$ (44). Table 3 shows $R_{A}$ values, and a RED value lower than 1 , was calculated for all solvents, indicating therefore they are good solvents for PLA. Hence the thermodynamic criteria of the methodology proposed to prepare homogenous electrospinnable solutions are achieved.

Table 3. RED values of the solvents used

\begin{tabular}{|l|c|c|}
\hline Solvent & $\mathrm{R}_{\mathrm{A}}$ & $\mathrm{R}_{\mathrm{A}} / \mathrm{R}_{\mathrm{AO}}=\mathrm{RED}$ \\
\hline $\mathrm{AC}$ & 5.21 & $5.21 / 11.26=0.46$ \\
\hline DMF & 8.30 & $8.30 / 11.26=0.74$ \\
\hline DX & 7.09 & $7.09 / 11.26=0.63$ \\
\hline CHL & 4.93 & $4.93 / 11.26=0.44$ \\
\hline
\end{tabular}

\subsection{Solution electrical properties and nanofibre morphology}

\section{$\underline{P L A}$ solutions in acetone $(A C)$}

Acetone (AC) was chosen for its low boiling point and lower toxicity compared with the most common solvents used to dissolve PLA. The $\chi$ and RED value, reported in Table 2 and Table 3, indicate that acetone is a good solvent for PLA. Figure 1 shows the change in nanofibre morphology on increasing the polymer concentration. Only beads were formed using PLA solution at concentration of 3 and $4 \% \mathrm{w} / \mathrm{v}$. A mixture of beads and a few nanofibres was formed from electrospinning of the PLA solution at a concentration of $5 \%$ $\mathrm{w} / \mathrm{v}$. Upon increasing the PLA concentration to $7.5 \% \mathrm{w} / \mathrm{v}$ more nanofibres were produced due to more entanglements between polymer chains and to higher viscoelastic forces that overcome the surface tension force. Beads were still produced up to a concentration of $10 \%$ $\mathrm{w} / \mathrm{v}$, and also their shape changed from irregular to spindle-like as the solution concentration increased. Defect-free nanofibres were collected using the PLA solutions at polymer concentrations of 12.5 and $15 \% \mathrm{w} / \mathrm{v}$. As the concentration further increased, electrospinning was difficult due to the higher viscosity of the solution. In fact, the fast evaporation of the solvent from the charged jet caused clogging of the needle (46).

Figure 2 shows the effect of polymer concentration on the mean nanofibre diameter. On increasing the polymer concentration bigger nanofibres were collected. The nanofibre diameter distribution was also determined. The mean diameter of nanofibres collected from a solution at concentration of $10 \% \mathrm{w} / \mathrm{v}$ was $220 \mathrm{~nm}$. The lower value of standard deviation $(109 \mathrm{~nm})$ for nanofibres collected using a solution at concentration of $10 \% \mathrm{w} / \mathrm{v}$, indicates a more homogeneous nanofibrous mat, although more beads were observed. 

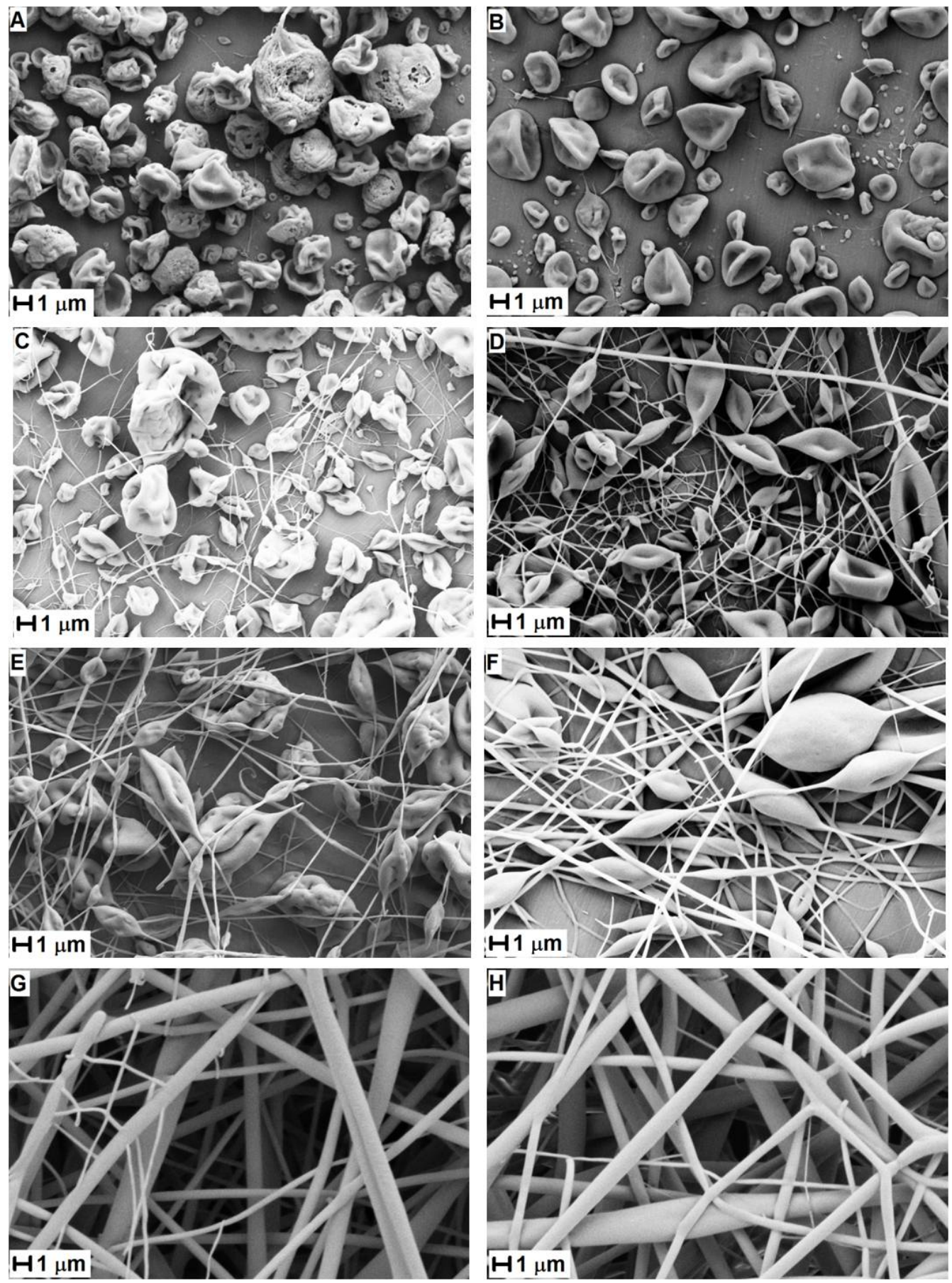

Figure 1. Effect of polymer concentration on nanofibre morphology - scanning electron micrographs of PLA nanofibres from solutions of PLA in AC at concentration (a) 3\% w/v, (b) $4 \% \mathrm{w} / \mathrm{v}$, (c) $5 \% \mathrm{w} / \mathrm{v}$, (d) $6 \% \mathrm{w} / \mathrm{v}$, (e) $7.5 \% \mathrm{w} / \mathrm{v}$, (f) $10 \% \mathrm{w} / \mathrm{v}$, (g) $12.5 \% \mathrm{w} / \mathrm{v}$, (h) $15 \% \mathrm{w} / \mathrm{v}$ (10000x). 

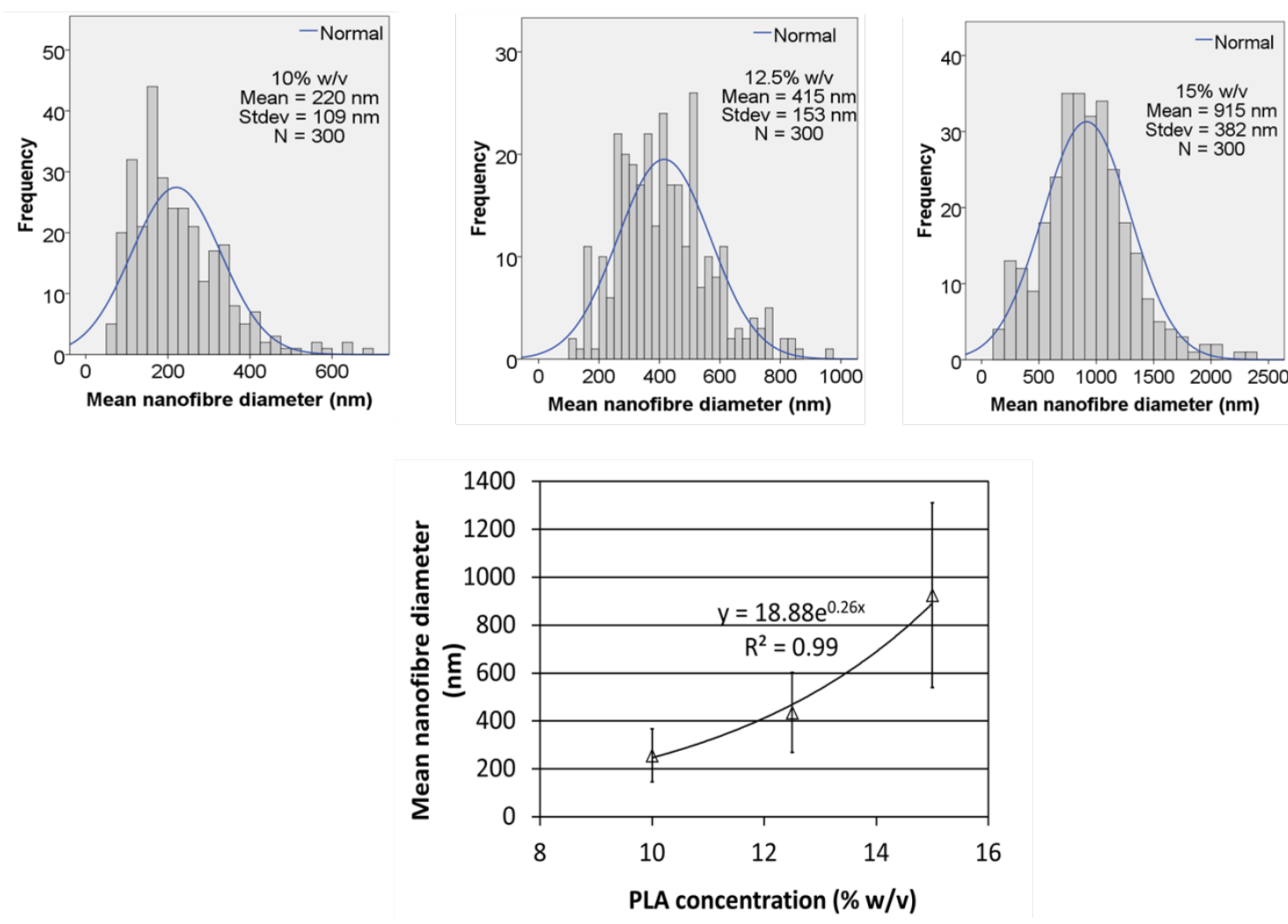

Figure 2. Effect of PLA concentration in AC solution on mean nanofibre diameter.

\section{$\underline{\text { PLA solutions in dimethylformamide (DMF) }}$}

As shown in Table 2 a $\chi$ value higher than 0.5 represents weak interactions between the polymer chains and solvent molecules. However, PLA homogeneously dissolved in DMF at all concentrations, as indicated by the RED value given (Table 3).

SEM images of nanofibres produced using solutions of PLA in DMF are shown in Figure 3. Only beads were collected using solutions of concentrations from 3 to $7.5 \% \mathrm{w} / \mathrm{v}$. A few nanofibres with a lot of beads were collected from the $10 \% \mathrm{w} / \mathrm{v}$ solution. A further increase in concentration resulted in the formation of continuous fibres, but beads were also collected. Since the interactions between PLA and DMF are weaker than those between PLA and AC, a higher amount of polymer is needed to form a sufficient number of entanglements with the solvent molecules, and therefore to produce continuous nanofibres.

Another parameter that has a significant effect on nanofibre morphology when comparing different solvent systems, is the dielectric constant $(\varepsilon)$ of the solvent $(47,48)$. Solvents with a larger $\varepsilon$ have a higher net charge density in solution, so more charges are carried by the jet resulting in smaller beads and thinner fibre diameters. DMF has a higher dielectric constant than AC and a higher surface tension (Table 1). It is clearly visible that beads collected from 
PLA solution in DMF at low concentrations are circular in shape (Figure 3) compared with the elliptical beads formed from PLA solutions in AC (Figure 1) probably due to the higher surface tension. However, thinner nanofibres can be collected from PLA solutions in DMF due to the higher dielectric constant (36.7), although a higher polymer concentration is needed to collect nanofibres as a result of the poor interaction between polymer and solvent. PLA solutions in DMF produced only beaded fibres at all concentrations, whereas PLA solutions with concentration higher than $20 \%$ w $/ \mathrm{v}$ were too viscous to be electrospun. The difference in the solubility parameters $\chi$ between DMF and PLA can be used as an indication for the suitability of DMF as a solvent for PLA. Though the RED value for DMF lower than 1 (Table 2) indicates the possibility of dissolution of PLA in DMF, the Flory-Huggins value of 1.03 is an indicator of the poor interaction between polymer and solvent molecules. Therefore defect-free nanofibres were not collected using only DMF to dissolve PLA. 


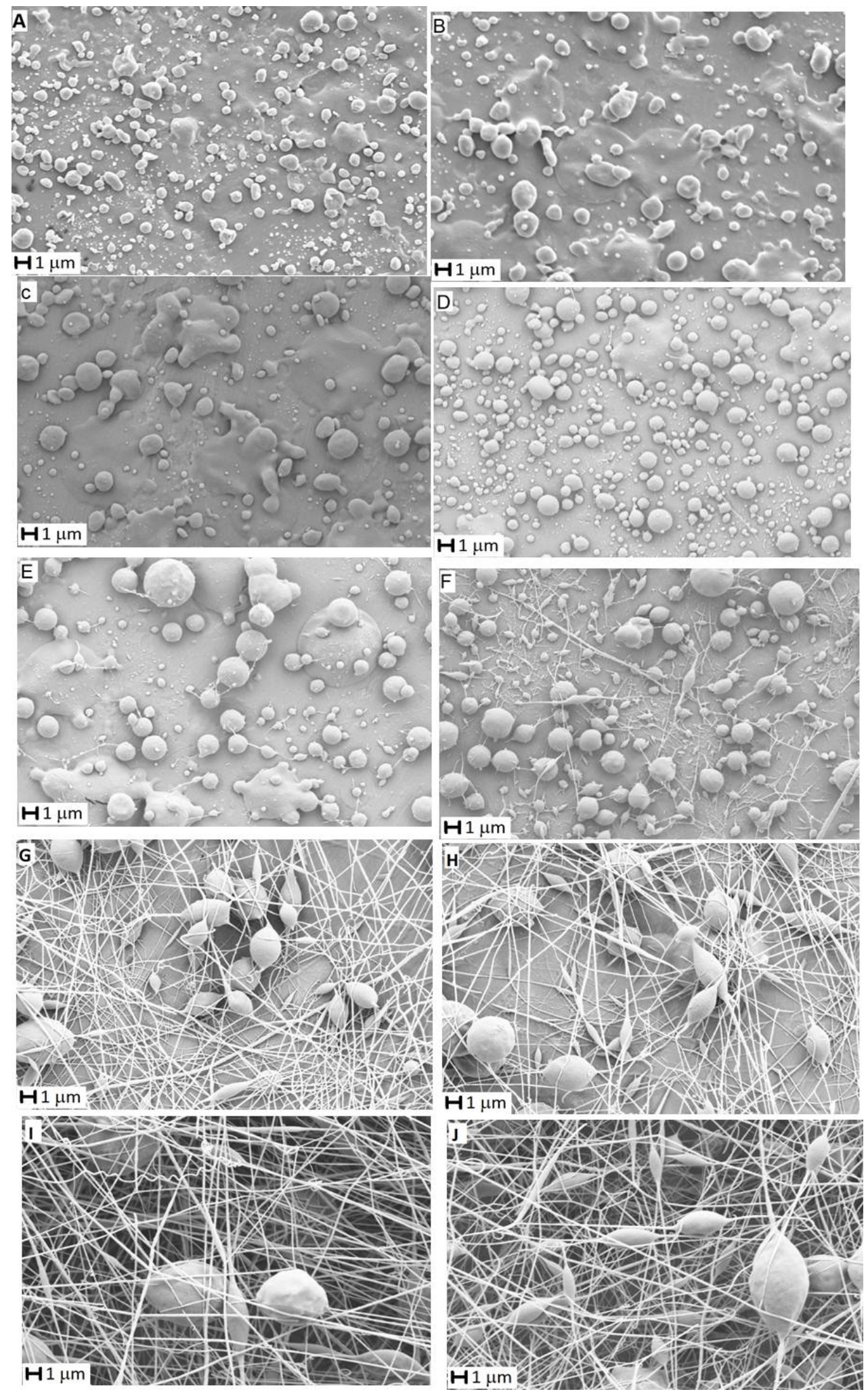

Figure 3. Effect of polymer concentration on nanofibre morphology - scanning electron micrographs of PLA nanofibres from solutions of PLA in DMF at concentration (a) $3 \% \mathrm{w} / \mathrm{v}$, (b) $4 \% \mathrm{w} / \mathrm{v}$, (c) $5 \% \mathrm{w} / \mathrm{v}$, (d) $6 \% \mathrm{w} / \mathrm{v}$, (e) $7.5 \% \mathrm{w} / \mathrm{v}$, (f) $10 \% \mathrm{w} / \mathrm{v}$, (g) $12.5 \% \mathrm{w} / \mathrm{v}$, (h) $15 \% \mathrm{w} / \mathrm{v}$, (i) $17.5 \% \mathrm{w} / \mathrm{v},(\mathrm{j}) 20 \% \mathrm{w} / \mathrm{v}(10000 \mathrm{x})$ 


\section{$\underline{\text { PLA solutions in AC/DMF }}$}

Despite DMF being unsuitable for the production of defect-free PLA nanofibres as a single solvent, when used in a solvent mixture, it showed beneficial results leading to smaller fibre diameters and a narrower diameter distribution due to higher dielectric constant.

PLA solutions in AC/DMF (50/50 v/v) were electrospun with the concentration of PLA varying from 3 to $15 \% \mathrm{w} / \mathrm{v}$. Figure 4 shows SEM images of the electrospun nanofibres collected using different polymer concentrations. Only beads were collected from PLA solutions at a concentration of 3\% w/v. Many beads and a few short fibres were collected at concentrations of 4 and $5 \% \mathrm{w} / \mathrm{v}$. On increasing the polymer concentration to $6 \% \mathrm{w} / \mathrm{v}$ more nanofibres were produced even though defects were still present. The PLA nanofibres contained beads up to a concentration of $10 \% \mathrm{w} / \mathrm{v}$. Above $12.5 \% \mathrm{w} / \mathrm{v}$ defect-free fibres could be collected.

The change in fibre morphology with increasing concentration can be attributed to competition between the surface tension and viscosity. An increase in the polymer concentration results in more chain entanglements and an increase in the solution viscosity. If the solution viscosity is low, the surface tension prevails, and therefore Rayleigh instability tends to form beads. On increasing the concentration, nanofibres and beads are both produced. Then on further increasing of the polymer concentration, the viscoelastic force suppresses the Rayleigh instability and defect-free nanofibres can be collected (49).

Results showed a significant decrease in nanofibre diameter and a significantly narrower and more uniform diameter distribution for nanofibres produced from PLA solutions in AC/DMF (Figure 5) compared with nanofibres collected from PLA solutions in AC (Figure 1). For example, the mean fibre diameter for nanofibres produced from a PLA solution in AC/DMF at $15 \% \mathrm{w} / \mathrm{v}$ was $500 \pm 162 \mathrm{~nm}$, whereas the mean diameter of nanofibres produced from a PLA solution in AC at the same concentration was $915 \pm 382 \mathrm{~nm}$. Due to the addition of DMF, which has a higher dielectric constant, as shown in Table 1, and which increases the conductivity of AC/DMF solutions, as shown in Table 4, the polymer jet is subjected to higher stretching that results in the production of smaller nanofibres. Also as shown in Table 2 the $\chi$ parameter of the mixture was calculated to be 0.49 , which is lower than 0.5 , indicating favourable polymer solvent interactions. These results indicate that although DMF is not suitable for electrospinning of PLA as a single solvent to produce defect-free fibres, it significantly improves the fibre morphology and the diameter distribution when added in a mixture with a good solvent like acetone. 

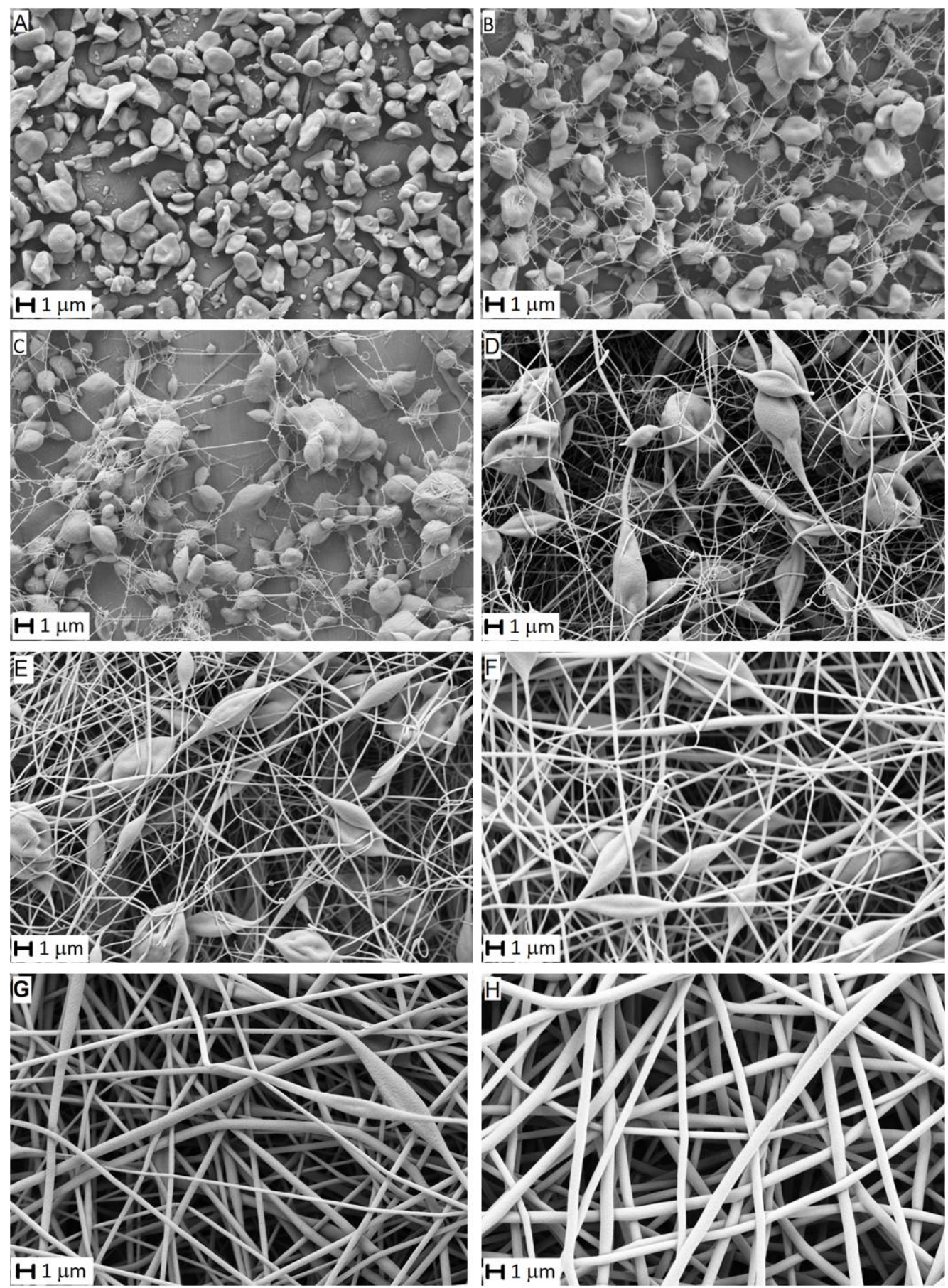

Figure 4. Effect of polymer concentration on nanofibre morphology - scanning electron micrographs of PLA nanofibres from solutions of PLA in AC/DMF at a ratio of 50/50 v/v at concentration (a) $3 \% \mathrm{w} / \mathrm{v}$, (b) $4 \% \mathrm{w} / \mathrm{v}$, (c) $5 \% \mathrm{w} / \mathrm{v}$, (d) $6 \% \mathrm{w} / \mathrm{v}$, (e) $7.5 \% \mathrm{w} / \mathrm{v}$, (f) $10 \% \mathrm{w} / \mathrm{v}$, (g) $12.5 \% \mathrm{w} / \mathrm{v}$, (h) $15 \% \mathrm{w} / \mathrm{v}(10000 \mathrm{x})$ 

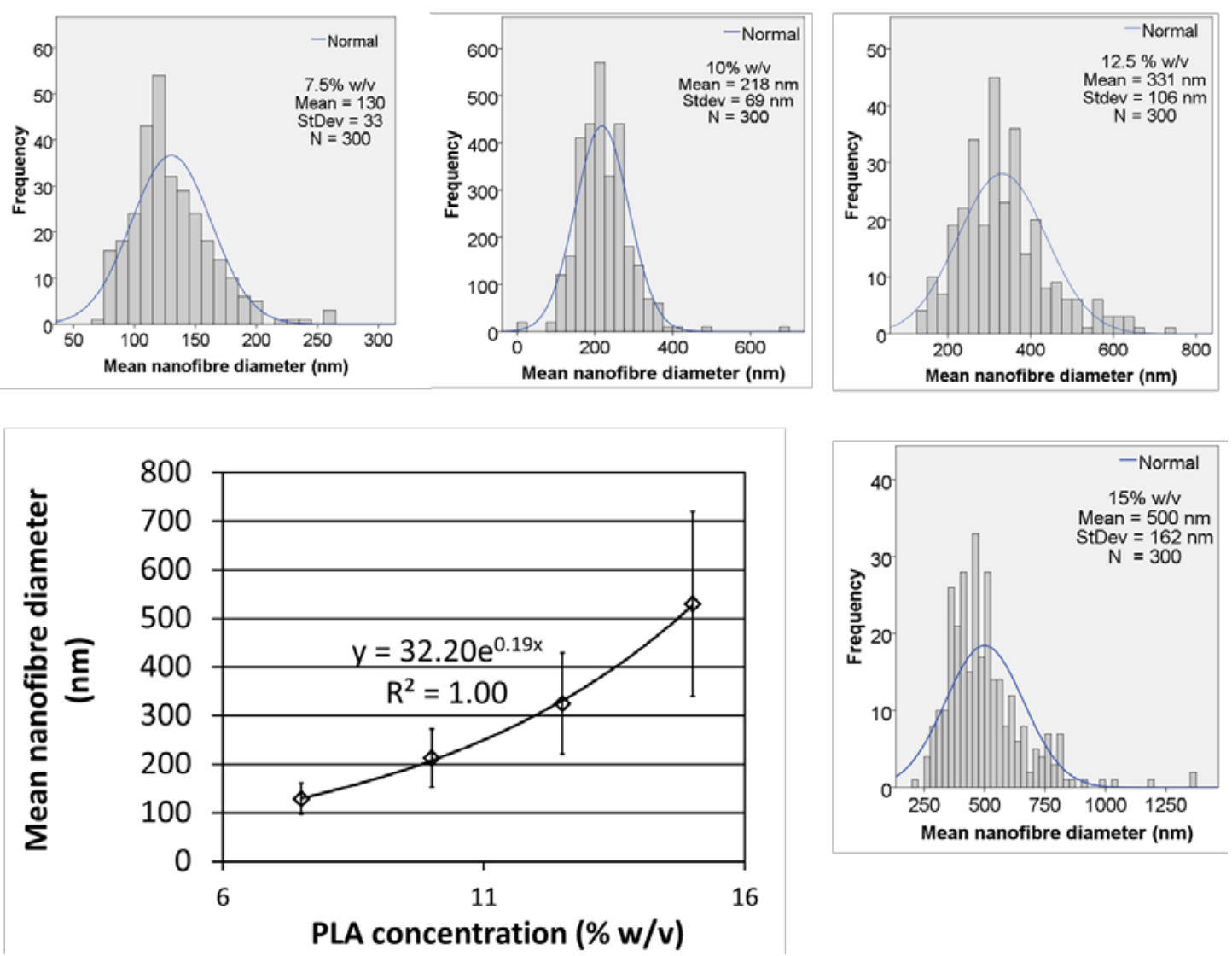

Figure 5. Effect of PLA concentration in AC/DMF (50/50 v/v) solution on mean nanofibre diameter.

Table 4. Surface tension $(\sigma)$ and solution conductivity $(K)$ of PLA solutions in AC, DMF, and AC/DMF at several concentrations.

\begin{tabular}{|c|c|c|c|c|c|c|}
\hline & \multicolumn{2}{|c|}{ AC } & \multicolumn{2}{c|}{ DMF } & \multicolumn{2}{c|}{ AC/DMF } \\
\hline PLA concentration $(\% \mathbf{w} / \mathbf{v})$ & $\boldsymbol{\sigma}(\mathbf{m N} / \mathbf{m})$ & $\mathbf{K}(\boldsymbol{\mu S} / \mathbf{c m})$ & $\boldsymbol{\sigma}(\mathbf{m N} / \mathbf{m})$ & $\mathbf{K}(\boldsymbol{\mu S} / \mathbf{c m})$ & $\boldsymbol{\sigma}(\mathbf{m N} / \mathbf{m})$ & $\mathbf{K}(\boldsymbol{\mu S} / \mathbf{c m})$ \\
\hline 1 & $/$ & $2.37 \pm 0.12$ & $/$ & $/$ & $/$ & $2.55 \pm 0.10$ \\
\hline 2 & $/$ & $2.09 \pm 0.11$ & $/$ & $/$ & $/$ & $2.19 \pm 0.03$ \\
\hline 3 & $23.63 \pm 0.10$ & $1.27 \pm 0.01$ & $37.10 \pm 0.16$ & $2.36 \pm 0.22$ & $29.60 \pm 0.16$ & $1.62 \pm 0.02$ \\
\hline 4 & $23.31 \pm 0.32$ & $0.71 \pm 0.03$ & $36.57 \pm 0.17$ & $2.46 \pm 0.20$ & $29.59 \pm 0.22$ & $2.09 \pm 0.04$ \\
\hline 5 & $23.50 \pm 0.18$ & $0.83 \pm 0.05$ & $36.20 \pm 0.38$ & $3.67 \pm 0.28$ & $29.85 \pm 0.13$ & $1.68 \pm 0.04$ \\
\hline 6 & $23.20 \pm 0.09$ & $/$ & $38.47 \pm 0.16$ & $2.65 \pm 0.06$ & $29.72 \pm 0.18$ & $/$ \\
\hline 7.5 & $23.40 \pm 0.64$ & $1.16 \pm 0.01$ & $37.24 \pm 0.22$ & $3.10 \pm 0.30$ & $29.52 \pm 0.22$ & $2.21 \pm 0.14$ \\
\hline 9 & $/$ & $1.02 \pm 0.13$ & $/$ & $3.08 \pm 0.04$ & $/$ & $2.69 \pm 0.14$ \\
\hline 10 & $23.39 \pm 0.43$ & $0.92 \pm 0.05$ & $38.37 \pm 0.17$ & $2.89 \pm 0.08$ & $29.49 \pm 0.18$ & $2.35 \pm 0.13$ \\
\hline 11 & $/$ & $0.82 \pm 0.02$ & $/$ & $3.19 \pm 0.13$ & $/$ & $2.69 \pm 0.10$ \\
\hline 12.5 & $23.32 \pm 0.15$ & $0.82 \pm 0.01$ & $37.42 \pm 0.21$ & $3.22 \pm 0.17$ & $29.76 \pm 0.32$ & $2.57 \pm 0.12$ \\
\hline 15 & $22.99 \pm 0.61$ & $0.87 \pm 0.01$ & $37.53 \pm 0.26$ & $3.58 \pm 0.16$ & $29.33 \pm 0.38$ & $2.74 \pm 0.11$ \\
\hline
\end{tabular}




\section{$\underline{P L A}$ solutions in DX,CHL and the mixtures DX/DMF and CHL/DMF}

1,4 dioxane and chloroform have Flory-Huggins parameters lower than 0.5, and RED values lower than 1 indicating that they are good solvents for PLA (Table 2 and Table 3). However no nanofibres were collected using PLA solution in DX at a concentration of $10 \% \mathrm{w} / \mathrm{v}$, as shown in Figure 6 A. Only beads were formed due to the combined effect of high surface tension and very low dielectric constant (Table 1). In fact during the experiment the solution accumulated at the needle tip and therefore it was necessary to stop the experiment and clean the needle. On increasing the polymer concentration to 15\% w/v (Figure 6 B), very few nanofibres were collected, but the higher solution viscosity (Table 5) inhibited the electrospinning process and the production of a nanofibrous web. In comparison, PLA solution in DMF at a concentration of 10 and 15\% w/v (Figure 3) allowed the production of more nanofibres, due to the higher dielectric constant of DMF compared with that of DX (Table 1) resulting therefore in higher solution conductivity (Table 5).
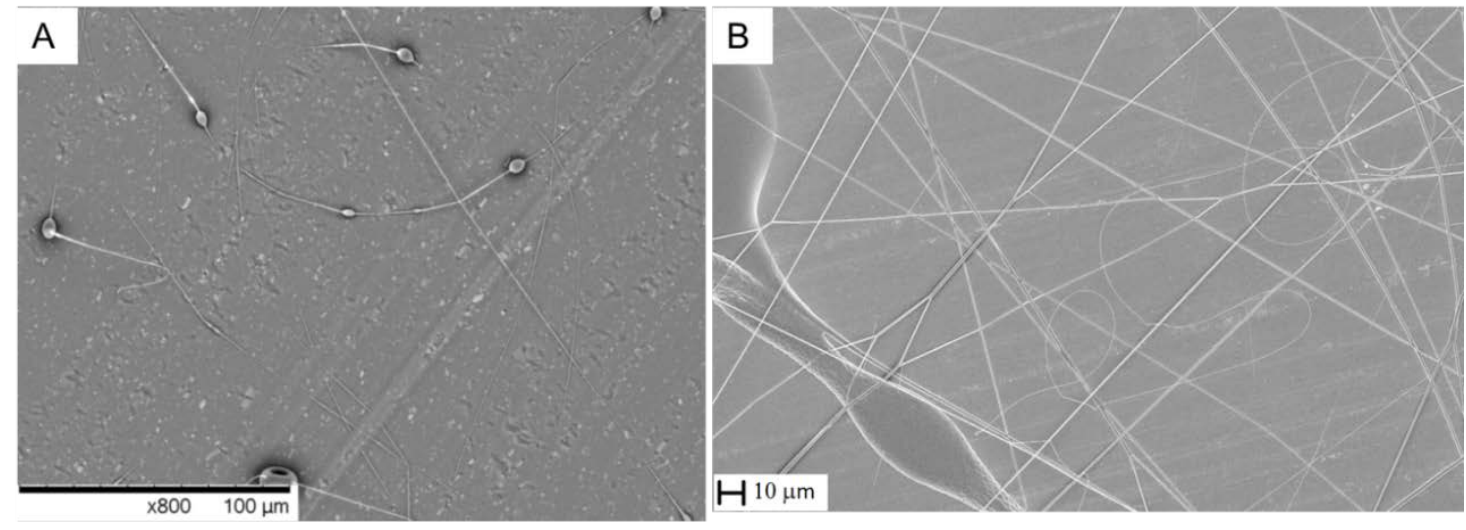

Figure 6. Scanning electron micrographs of PLA nanofibres from solutions of PLA in DX at a concentration of (A) $10 \% \mathrm{w} / \mathrm{v}$ and (B) $15 \% \mathrm{w} / \mathrm{v}$.

Table 5. Solution viscosity, surface tension and conductivity of PLA solution in CHL and CHL/DMF.

\begin{tabular}{|l|c|c|c|c|}
\hline Solvent system & PLA concentration $\mathbf{( \%} \mathbf{w} / \mathbf{v})$ & $\boldsymbol{\eta}(\mathbf{c P})$ & $\boldsymbol{\sigma}(\mathbf{m N} / \mathbf{m})$ & $\mathbf{K}(\boldsymbol{\mu S} / \mathbf{c m})$ \\
\hline \multirow{2}{*}{ CHL } & 10 & $354.9 \pm 17.5$ & $30.80 \pm 0.27$ & 0.01 \\
\cline { 2 - 5 } & 15 & $1427 \pm 165$ & $31.62 \pm 0.23$ & 0.01 \\
\hline \multirow{2}{*}{ CHL/DMF } & 10 & $205.1 \pm 6.3$ & $33.64 \pm 0.38$ & $1.68 \pm 0.05$ \\
\cline { 2 - 5 } & 15 & $980.1 \pm 75.0$ & $34.24 \pm 0.17$ & $1.23 \pm 0.03$ \\
\hline \multirow{2}{*}{ DX } & 10 & $435.3 \pm 10.7$ & $35.52 \pm 0.26$ & 0.01 \\
\hline \multirow{2}{*}{ DX/DMF } & 15 & $2073 \pm 460.7$ & $36.02 \pm 0.36$ & 0.01 \\
\cline { 2 - 5 } & 10 & $275.4 \pm 24.2$ & $36.32 \pm 0.51$ & $3.08 \pm 0.10$ \\
\cline { 2 - 5 } & 15 & $1031 \pm 51.2$ & $36.96 \pm 0.30$ & $2.77 \pm 0.11$ \\
\hline
\end{tabular}


The addition of DMF to DX in solution increased the solution conductivity and decreased the viscosity as shown in Table 5. Nanofibres with few beads were collected from PLA solution in DX/DMF at both polymer concentrations (Figure 7). The diameter of 100 fibres was measured and the nanofibre diameter distribution is shown in Figure 8. On increasing the polymer concentration nanofibre mean diameter increased from 266 to $377 \mathrm{~nm}$ due to the increase of solution viscosity as shown in Table 5.
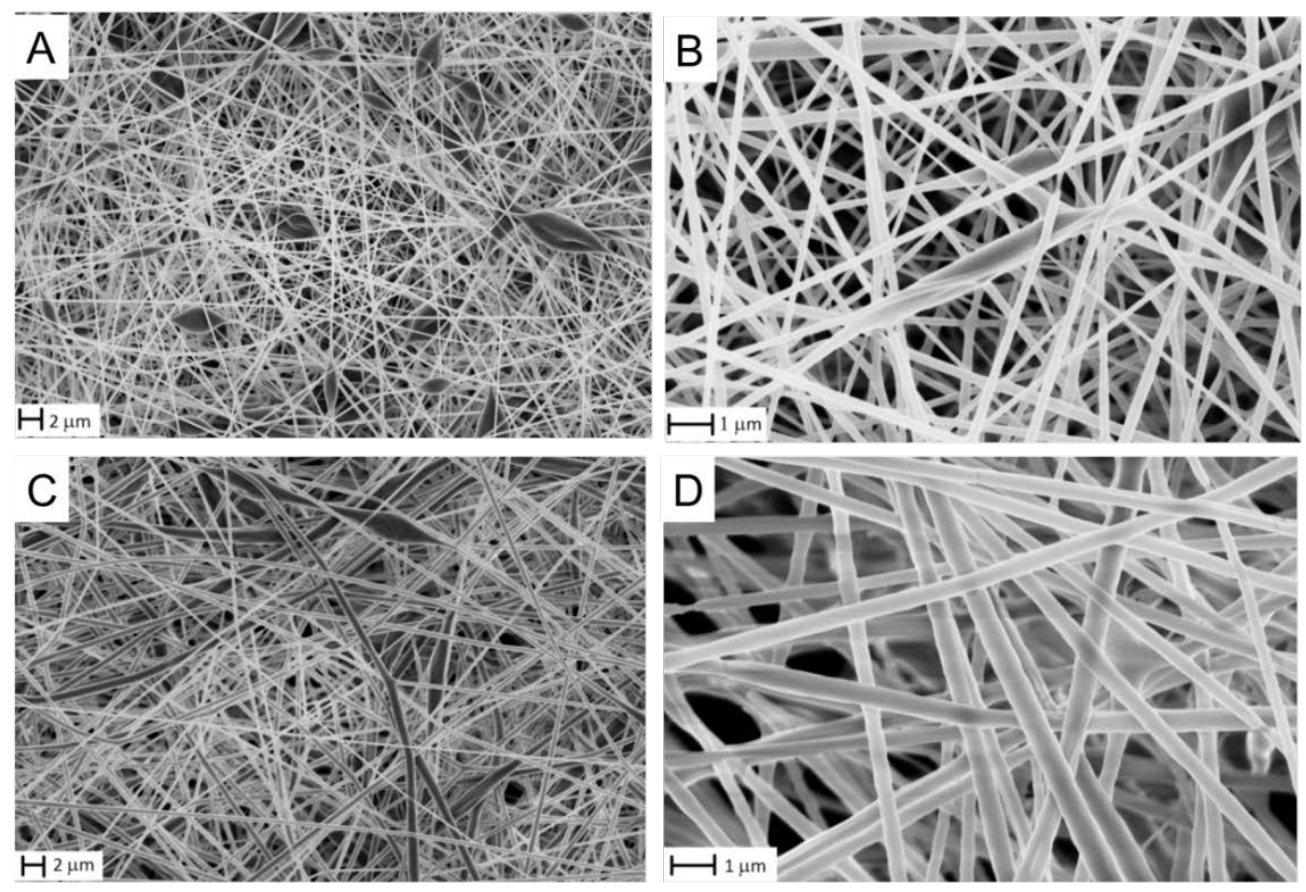

Figure 7. Scanning electron micrographs of PLA nanofibres from solutions of PLA in DX/DMF (50/50 v/v) at concentration of 10\% w/v 5000x (A) and 20000x (B), and concentration of 15\% w/v 5000x (C) and 20000x (D).
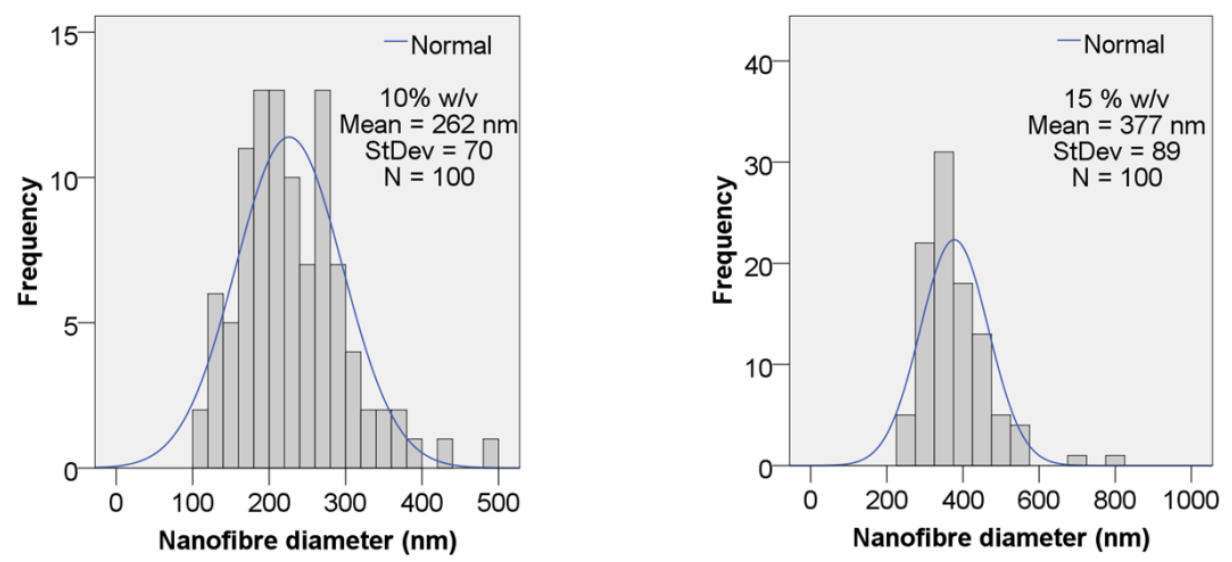

Figure 8. Diameter distribution of nanofibres collected from PLA solution in DX/DMF $(50 / 50 \mathrm{v} / \mathrm{v})$ at concentration of $10 \% \mathrm{w} / \mathrm{v}$ and $15 \% \mathrm{w} / \mathrm{v}$. 
In the case of PLA solutions in CHL at concentration of 10 and $15 \%$ w/v, only a few beaded nanofibres were collected as shown in Figure $9 \mathrm{~A}$ and B. A nanofibrous mat could not be formed in 15 minutes as it was formed with AC. The low dielectric constant of CHL (4.8) does not help the production of continuous nanofibres due to low surface charge density. Moreover, due to the high solvent volatility clogging of the needle often occurred. Although CHL and AC have a similar boiling point, AC is a polar solvent with a high dielectric constant (20.6) which contributes to the successful production of nanofibres from PLA solution in AC (Figure 1). A few more nanofibres seemed to be collected using PLA solution in CHL compared with PLA solution in DX probably due to the slighter lower surface tension and solution viscosity as shown in Table 5. However no nanofibrous webs were collected as shown in Figure 7 and Figure 9.

The addition of DMF to CHL enhanced the production of nanofibres and caused the elimination of beads as shown from the morphological observation in Figure $9 \mathrm{C}$ to $\mathrm{F}$. The higher productivity of defect-free nanofibres with the mixture CHL/DMF is achieved as a result of the increased surface charge density due to the addition of DMF which led to an increase of solution conductivity (Table 5). Moreover on increasing the polymer concentration from 10 to $15 \%$ the mean fibre diameter increased from $153 \mathrm{~nm}$ to $466 \mathrm{~nm}$, as expected due to the increase of solution viscosity. Similar results were presented by Touny et al (38) where the spinnability of PLA in the presence of halloysite nanotubes was enhanced by the addition of DMF to CHL solution. Uniform and defect-free nanofibres with a mean diameter of approximately $100 \mathrm{~nm}$ were produced using a mixture of CHL/DMF at a ratio of $3: 1$.

Hence the second step of optimising the solution electrical properties is met by the addition of DMF to AC, CHL or DX. 

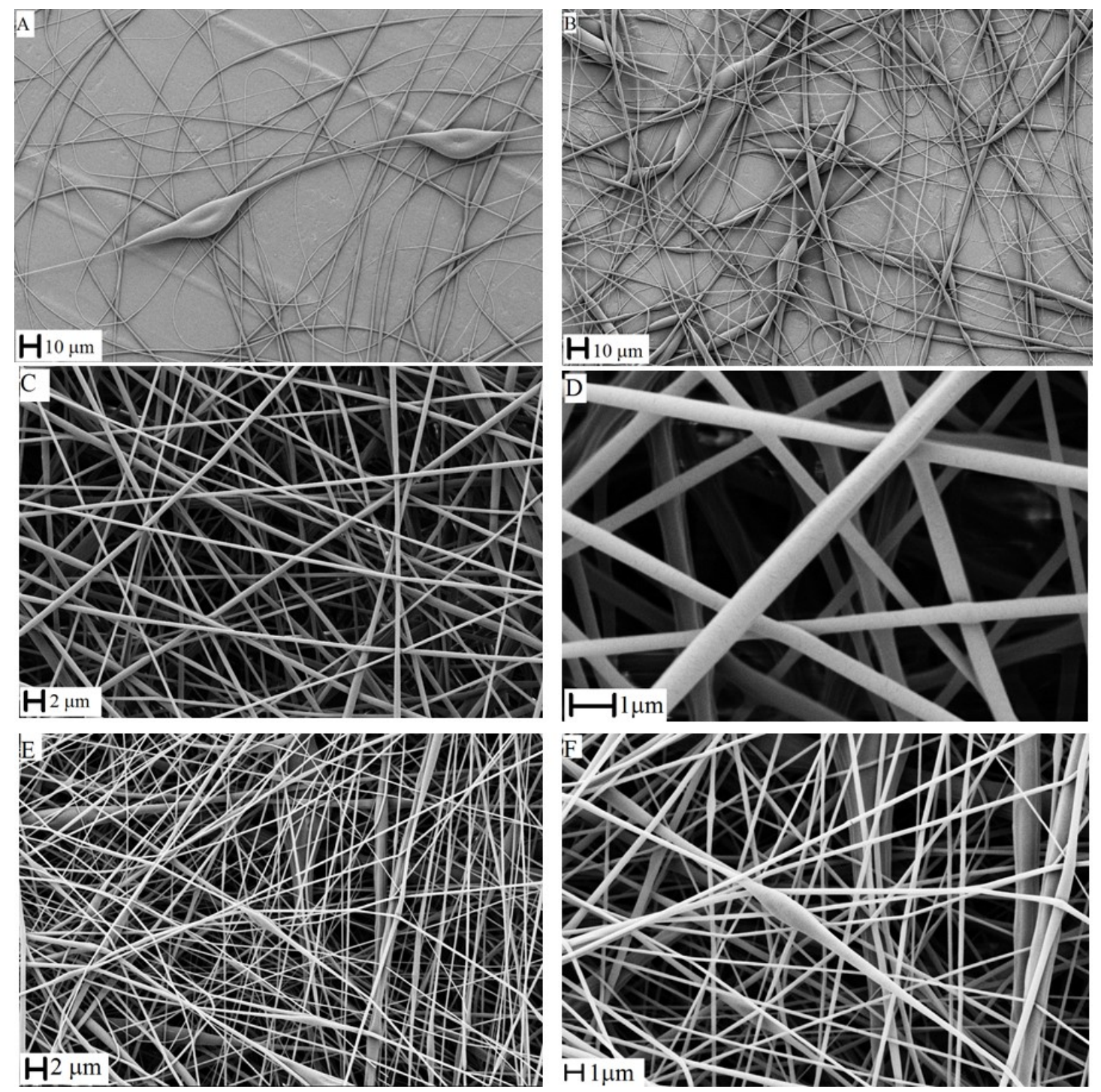

Figure 9. Scanning electron micrographs of PLA nanofibres from solutions of PLA in chloroform (CHL) at concentration of (A) 10\% w/v (1000x), (B) 15\% w/v (1000x), and in CHL/DMF (50/50 v/v) at concentration of (C) 10\% w/v (5000x), (D) 10\% w/v (25000x), (E) 15\% w/v (5000x), (F) 15\% w/v (10000x). 

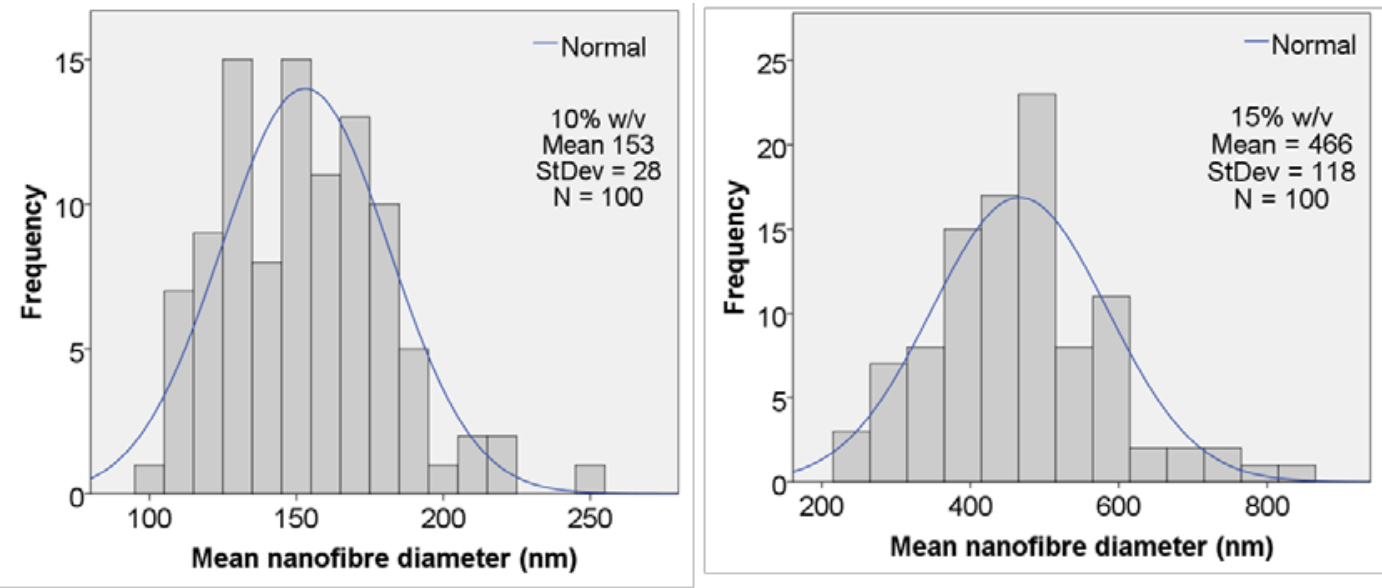

Figure 10. Effect of PLA concentration in AC/DMF (50/50 v/v) solution on mean nanofibre diameter

\subsection{Critical entanglement concentration and solution viscosity}

Once the thermodynamic criteria and the electrical property criteria are met, the third step involves the prediction of the entanglement concentration for the production of defect-free nanofibres.

Rotational tests were performed for all PLA solutions to determine the shear solution viscosity. The viscosity value was approximated from the flow curve by using the value at shear rate of $10 \mathrm{~s}^{-1}$. Figure 11, Figure 12 and Figure 13 show the log-log plot of viscosity as a function of PLA concentration in solutions AC, DMF and AC/DMF respectively. The values of overlap and entanglement concentrations, $C^{*}$ and $C_{e}$ respectively, for all solvent systems, are reported in Table 6.

Regarding PLA solutions in AC, three regimes were found from the plot of viscosity as shown in Figure 11. The rapid viscosity increase at about $6 \% \mathrm{w} / \mathrm{v}$ suggests the existence of chain entanglements occurring around this concentration. It indicates the transition from the unentangled to the entangled regime. Results showed that solution viscosity is proportional to $\mathrm{C}^{0.8}$ in the dilute regime, to $\mathrm{C}^{2.2}$ in the semidilute unentangled regime, and thereafter is proportional to $\mathrm{C}^{4.1}$ in the semidilute entangled regime. 


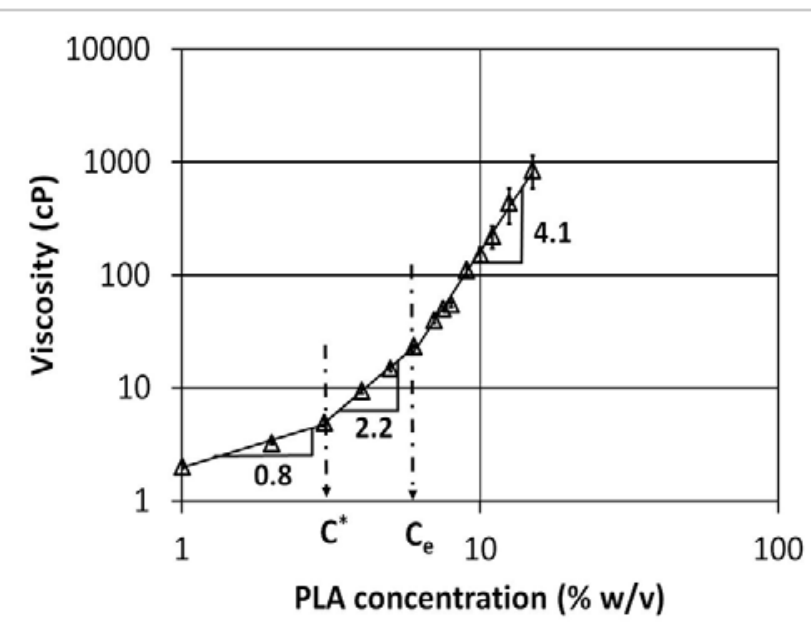

\begin{tabular}{|c|c}
\hline PLA concentration $(\% \mathbf{w} / \mathbf{v})$ & Viscosity $(\mathbf{c P})$ \\
\hline 1 & $2.03 \pm 0.10$ \\
\hline 2 & $3.24 \pm 0.08$ \\
\hline 3 & $4.96 \pm 0.33$ \\
\hline 4 & $9.36 \pm 0.45$ \\
\hline 5 & $14.97 \pm 0.96$ \\
\hline 6 & $23.57 \pm 0.61$ \\
\hline 7 & $40.01 \pm 2.66$ \\
\hline 7.5 & $50.72 \pm 2.17$ \\
\hline 8 & $55.03 \pm 2.70$ \\
\hline 9 & $111.7 \pm 14.9$ \\
\hline 10 & $151.8 \pm 22.0$ \\
\hline 11 & $223.5 \pm 50.1$ \\
\hline 12.5 & $435.0 \pm 152.4$ \\
\hline 15 & $855.8 \pm 271.8$ \\
\hline
\end{tabular}

Figure 11. Effect of the polymer concentration on the viscosity of PLA solution in AC.

The morphological observations of nanofibres from PLA solution in AC shown in Figure 1 are consistent with the prediction from the solution viscosity data. Figure $1 \mathrm{D}$ showed that nanofibres are first formed at a concentration of $6 \% \mathrm{w} / \mathrm{v}$. The optimum concentration for defect-free nanofibre production is between 2 and 2.5 times the entanglement concentration i.e. $12.5 \%$ w/v (see Figure $1 \mathrm{G}$ ).

Similarly, three regimes were found for PLA solutions in DMF as shown in Figure 12. The entanglement concentration, found to be about $10 \% \mathrm{w} / \mathrm{v}$, is higher than the concentration found for PLA solution in AC. An explanation is the poor interaction between PLA and DMF, as demonstrated by the value of $\chi$ being higher than 0.5 (Table 2). The solution viscosity was proportional to $C^{2.4}$ in the semidilute unentangled regime and to $C^{4.4}$ in the semidilute entangled regime. Figure $3 \mathrm{G}$ shows that nanofibres are first collected at a concentration of $12.5 \% \mathrm{w} / \mathrm{v}$, indicating good agreement for the predicted value of $\mathrm{C}_{e}$ between the morphological observations and the solution viscosity data. The optimum concentration should be around $25 \% \mathrm{w} / \mathrm{v}$, but this solution is too viscous to electrospin.

Similarly Wang et al (50) electrospun poly(lactic acid) solutions in dimethylformamide (DMF) and they found that only droplets were collected below the entanglement concentration of about $10 \% \mathrm{w} / \mathrm{v}$, whereas a minimum concentration of $19 \% \mathrm{w} / \mathrm{v}$ was needed to obtain defect-free nanofibres.

DMF is not a good solvent for PLA, therefore the polymer coils contract and the entanglements between the polymer chains are weak. This results in difficulties for the stretching of the polymeric jet under the electric field, and formation of beads or beaded nanofibres occurs. On the other hand, for a good solvent (AC) interaction between polymer chains and solvent molecules are energetically favorable. This cause polymer coils to expand, entanglements are strong and therefore nanofibres are produced. 


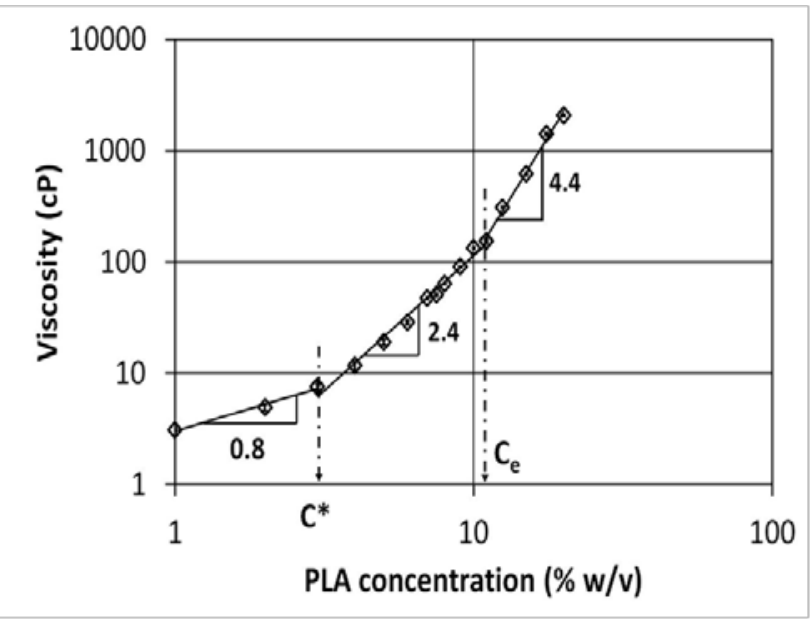

\begin{tabular}{|c|c|}
\hline PLA concentration (\% w/v) & Viscosity (cP) \\
\hline 1 & $3.10 \pm 0.14$ \\
\hline 2 & $4.95 \pm 0.31$ \\
\hline 3 & $7.55 \pm 0.34$ \\
\hline 4 & $11.70 \pm 0.65$ \\
\hline 5 & $19.00 \pm 1.23$ \\
\hline 6 & $28.82 \pm 0.93$ \\
\hline 7 & $47.44 \pm 0.39$ \\
\hline 7.5 & $50.75 \pm 3.84$ \\
\hline 8 & $63.79 \pm 9.81$ \\
\hline 9 & $90.74 \pm 1.37$ \\
\hline 10 & $133.88 \pm 5.98$ \\
\hline 11 & $154.47 \pm 4.98$ \\
\hline 12.5 & $309.55 \pm 13.46$ \\
\hline 15 & $619.35 \pm 38.29$ \\
\hline 17.5 & $1411.01 \pm 9.90$ \\
\hline 20 & $2059.67 \pm 116.65$ \\
\hline
\end{tabular}

Figure 12. Effect of the polymer concentration on the viscosity of PLA solution in DMF.

Figure 13 shows the plot of viscosity versus concentration of PLA solution in AC/DMF. Three regimes were also established. The results show good agreement with the concentration exponent of PLA solution in AC and DMF in the semidilute unentangled regime $\left(\eta \sim C^{2.7}\right)$, although a slightly weaker dependence of viscosity on the polymer concentration was found in the entangled regime $\left(\eta \sim C^{3.6}\right)$. The entanglement concentration $C_{e}$ calculated from the log-log plot is $7.0 \% \mathrm{w} / \mathrm{v}$, slightly higher compared with $\mathrm{C}_{\mathrm{e}}$ of PLA solutions in acetone. The morphological observations (Figure 4) are consistent with these results. Mostly nanofibres with some beads were first formed at a concentration of $7.5 \% \mathrm{w} / \mathrm{v}$ as shown in Figure 4 D. Defect-free nanofibres are produced at a concentration of $15 \%$ w/v (Figure $4 \mathrm{H}$ ) which is about 2 times the entanglement concentration (Table 6). The interactions between AC, DMF and PLA in solution affect the polymer chain entanglements, and therefore the stretching of the jet under the electric field. 


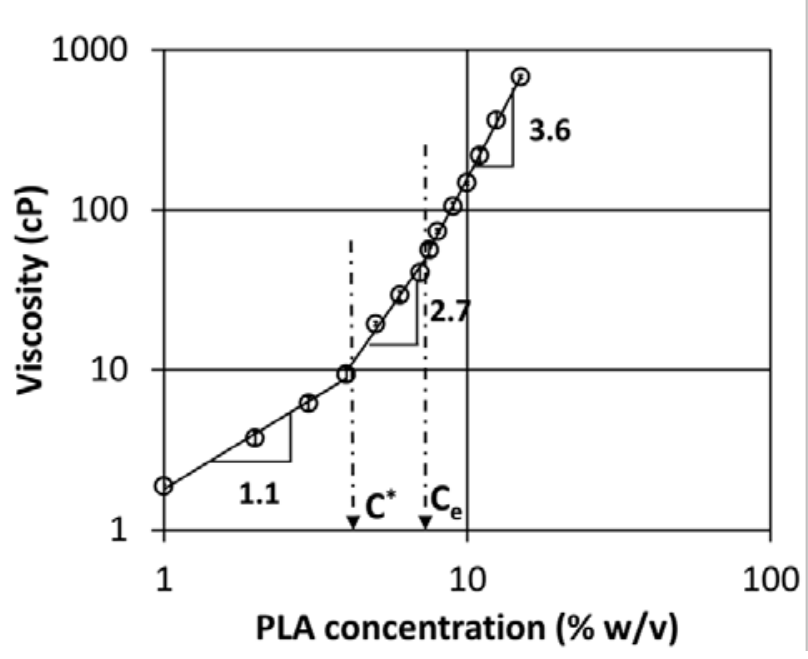

\begin{tabular}{|c|c}
\hline PLA concentration (\% w/v) & Viscosity (cP) \\
\hline 1 & $1.87 \pm 0.05$ \\
\hline 2 & $3.74 \pm 0.34$ \\
\hline 3 & $6.21 \pm 0.57$ \\
\hline 4 & $9.37 \pm 0.91$ \\
\hline 5 & $19.46 \pm 0.63$ \\
\hline 6 & $29.30 \pm 2.03$ \\
\hline 7 & $40.77 \pm 4.93$ \\
\hline 7.5 & $56.46 \pm 2.092$ \\
\hline 8 & $73.49 \pm 5.69$ \\
\hline 9 & $105.1 \pm 3.7$ \\
\hline 10 & $147.9 \pm 19.8$ \\
\hline 11 & $219.1 \pm 42.6$ \\
\hline 12.5 & $364.6 \pm 15.7$ \\
\hline 15 & $679.9 \pm 45.9$ \\
\hline
\end{tabular}

Figure 13. Effect of the polymer concentration on the viscosity of PLA solution in AC/DMF.

Table 6. Value of overlap $\left(C^{*}\right)$ and entanglement $\left(C_{e}\right)$ concentration for all solvent systems.

\begin{tabular}{|c|c|c|c|c|c|}
\hline \multirow[b]{2}{*}{ Solvent } & \multicolumn{5}{|c|}{ From plot specific viscosity-concentration } \\
\hline & $\begin{array}{c}\text { Dilute } \\
\text { regime }\end{array}$ & $\begin{array}{c}\text { Semidilute } \\
\text { unentangled regime }\end{array}$ & $\begin{array}{c}\text { Semidilute } \\
\text { entangled regime }\end{array}$ & $\begin{array}{c}C^{*} \\
(\% \mathrm{w} / \mathrm{v})\end{array}$ & $\begin{array}{c}\mathrm{C}_{\mathrm{e}} \\
(\% \mathrm{w} / \mathrm{v})\end{array}$ \\
\hline $\mathrm{AC}$ & $\eta \sim \mathrm{C}^{0.8}$ & $\eta \sim C^{2.2}$ & $\eta \sim C^{4.1}$ & 3.0 & 6.3 \\
\hline DMF & $\eta \sim \mathrm{C}^{0.9}$ & $\eta \sim C^{2.6}$ & $\eta \sim C^{4.4}$ & 4.0 & 10.2 \\
\hline $\mathrm{AC} / \mathrm{DMF}$ & $\eta \sim \mathrm{C}^{1.1}$ & $\eta \sim C^{2.7}$ & $\eta \sim C^{3.6}$ & 3.7 & 7.1 \\
\hline
\end{tabular}

\subsection{Critical entanglement concentration and elastic (G') and plastic (G”) moduli}

Measurements of elastic and plastic moduli were performed due to the importance of the viscoelasticity of polymer jet which is stretched during the electrospinning process. The results for PLA solutions in the solvent systems DMF and AC/DMF are shown in Figure 14. No results are reported for PLA solution in AC because the high volatility of AC resulted in no reproducible oscillatory measurements. The plasticity (G”) of the solution at any concentration is always higher than the elasticity ( $G^{\prime}$ ) for both solvent systems, DMF and AC/DMF, as shown in Figure 14.

A change of slope is clearly visible for the values of elastic modulus $G^{\prime}$ at a concentration around $9.8 \% \mathrm{w} / \mathrm{v}$ for the PLA solution in DMF, which is approximately the same as the entanglement concentration $\left(\mathrm{C}_{\mathrm{e}}\right)$ found from the log-log plot of viscosity as shown in Table 6 $(10.2 \% \mathrm{w} / \mathrm{v})$. Similarly, there is a change of slope of G' for the PLA solution in AC/DMF. This occurs at a concentration of $7.7 \% \mathrm{w} / \mathrm{v}$, which is in good agreement with the value of $7.1 \%$ $\mathrm{w} / \mathrm{v}$ for the entanglement concentration $\left(\mathrm{C}_{\mathrm{e}}\right)$ found from the viscosity measurements (Table 6). 
The higher entanglement concentration, $C_{e}$, for the PLA solution in DMF compared with $C_{e}$ of the PLA solution in AC/DMF, is related to the poor interaction between DMF and PLA $(51,52)$ as shown by the value of $\chi$ (Table 2$)$.

The results revealed that the value of entanglement concentration $C_{e}$ can be determined by both solution viscosity and viscoelasticity measurements.

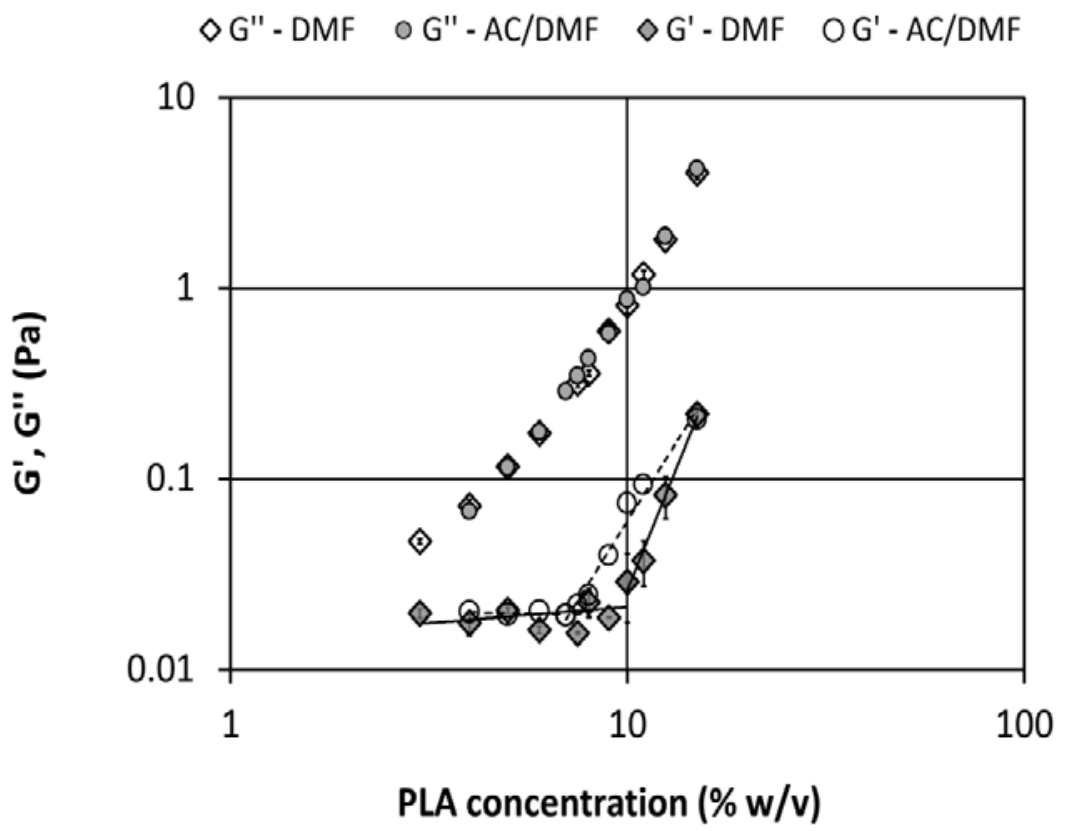

Figure 14. Effect of PLA concentration on elastic (G') and plastic (G”) modulus of PLA solution in DMF (left) and AC/DMF (right).

\section{Conclusions}

The main objective of this study was to propose a methodology for the selection of solvent systems to produce poly(lactic acid) electrospinnable solutions that form defect-free PLA fibres with narrow diameter distributions. PLA nanofibres were produced by the electrospinning process from PLA solutions in AC, DMF, AC/DMF, DX, CHL, DX/DMF and CHL/DMF.

The first step was to select the most suitable solvent using a thermodynamic approach. The Flory-Huggins parameter is lower than 0.5 for PLA solution in AC, CHL and DX, indicating that they are good solvents for PLA, whereas $\chi$ is higher than 0.5 for PLA solution in DMF representing poor interactions between solvent molecules and polymeric chains. However the RED values are a better indication of the polymer solubility. All solvent systems used in this work present RED values lower than 1 indicating good dissolution of the polymer. In fact, it was possible to dissolve PLA in all solvent system and form homogeneous solutions. 
The second step was to optimise the solution electrical properties to produce defect-free nanofibres with narrow diameter distribution. Although DX, CHL and DMF did not produce defect-free fibres when used as single solvents, the first two due to their low dielectric constants and the last probably due to its high boiling point and $\chi$ parameter, when DX and CHL were combined in a binary mixture with DMF defect-free fibres were produced. The addition of a solvent with high dielectric constant enables the formation of defect-free fibres.

The third step was to choose the optimum polymer concentration to collect defect-free nanofibres. The effect of the polymer concentration on the solution viscosity showed a sharp increase of viscosity and the elastic modulus at chain entanglement concentration, $\mathrm{C}_{\mathrm{e}}$, of approximately $6 \% \mathrm{w} / \mathrm{v}$ and $7 \% \mathrm{w} / \mathrm{v}$ for PLA solution in AC and AC/DMF, respectively, whereas higher entanglement concentration $(10.2 \% \mathrm{w} / \mathrm{v})$ was found for PLA solution in DMF. Nanofibres were first formed at a concentration about $C_{e}$ as shown from the morphological observation, while defect-free nanofibres at a concentration about 2 or 2.5 times $\mathrm{C}_{\mathrm{e}}$.

Summarizing the observations, the methodology proposed in this work follows three steps:

1- solubility parameter criteria ( $\chi$ and RED);

2- high dielectric constant (polar solvents);

3- polymer concentration higher than the entanglement concentration $\mathrm{C}_{\mathrm{e}}$.

\section{References}

1. Guarino V, Cirillo V, Taddei P, Alvarez-Perez M a, Ambrosio L. Tuning size scale and crystallinity of PCL electrospun fibres via solvent permittivity to address hMSC response. Macromolecular bioscience. 2011;11(12):1694-705.

2. Luo CJ, Nangrejo M, Edirisinghe M. A novel method of selecting solvents for polymer electrospinning. Polymer. 2010;51(7):1654-62.

3. Wannatong L, Sirivat A, Supaphol P. Effects of solvents on electrospun polymeric fibers: preliminary study on polystyrene. Polymer International. 2004;53(11):1851-9.

4. Antoniou E, Alexandridis P. Polymer conformation in mixed aqueous-polar organic solvents. European Polymer Journal. 2010;46(2):324-35.

5. Miller-Chou BA, Koenig JL. A review of polymer dissolution. Progress in Polymer Science. 2003;28(8):1223-70.

6. De Gennes P-G. Scaling Concepts in Polymer Physics. London: Cornell University Press; 1979. p. 69-97.

7. $\quad$ Flory PJ. Principles of Polymer Chemistry. Ithaca, NY: Cornell University Press; 1953. 
8. Pattamaprom C, Hongrojjanawiwat W, Koombhongse P, Supaphol P, Jarusuwannapoo $\mathrm{T}$, Rangkupan R. The influence of solvent properties and functionality on the electrospinnability of polystyrene nanofibers. Macromolecular Materials and Engineering. 2006;291(7):840-7.

9. Koenhen DM, Smolders CA. The determination of solubility parameters of solvents and polymers by means of correlations with other physical quantities. Journal of Applied Polymer Science. 1975;19(4):1163-79.

10. Ferdinand Rodriguez. Principles of Polymer Systems. Fourth. Washington: Taylor and Francis; 1996. p. 30-43.

11. Gedde UW. Polymer Physics. 1995th ed. London: Chapman \& Hall; 1995. p. 54-69.

12. Lee KH, Kim HY, Khil MS, Ra YM, Lee DR. Characterization of nano-structured poly(ع-caprolactone) nonwoven mats. Polymer Journal. 2003;44:1287-94.

13. Gu X, Song X, Shao C, Zeng P, Lu X, Shen X, et al. Electrospinning of poly(butylenecarbonate): effect of solvents on the properties of the nanofibers film. International journal of electrochemical science. 2014;9:8045-56.

14. Lee KH, Kim HY, La YM, Lee DR, Sung NH. Influence of a mixing solvent with tetrahydrofuran and N,N-dimethylformamide on electrospun poly(vinyl chloride) nonwoven mats. Journal of Polymer Science Part B: Polymer Physics. 2002 Oct 1;40:2259-68.

15. Katsogiannis KAG, Vladisavljević GT, Georgiadou S. Porous electrospun polycaprolactone (PCL) fibres by phase separation. European Polymer Journal [Internet]. 2015 Aug [cited 2016 Feb 4];69:284-95. Available from: http://linkinghub.elsevier.com/retrieve/pii/S0014305715000403

16. Brown WH, Iverson BL, Anslyn E, Foote CS. Organic Chemistry. Sixth. Brooks/Cole; 2009. p. 356.

17. Hsu C-M, Shivkumar S. N,N-Dimethylformamide additions to the solution for the electrospinning of poly( $\varepsilon$-caprolactone) nanofibers. Macromolecular Materials and Engineering. 2004 Apr;289(4):334-40.

18. Deitzel JM, Kleinmeyer J, Harris D, Beck Tan NC. The effect of processing variables on the morphology of electrospun nanofibers and textiles. Polymer. 2001 Jan;42(1):261-72.

19. Megelski S, Stephens JS, Chase DB, Rabolt JF. Micro- and Nanostructured Surface Morphology on Electrospun Polymer Fibers. Macromolecules. 2002;35:8456-66.

20. Choktaweesap N, Arayanarakul K, Aht-ong D, Meechaisue C, Supaphol P. Electrospun Gelatin Fibers: Effect of Solvent System on Morphology and Fiber Diameters. Polymer Journal [Internet]. 2007 [cited 2013 Jun 26];39(6):622-31. Available from: http://www.nature.com/doifinder/10.1295/polymj.PJ2006190 
21. Bonino CA, Krebs MD, Saquing CD, Jeong SI, Shearer KL, Alsberg E, et al. Electrospinning alginate-based nanofibers: From blends to crosslinked low molecular weight alginate-only systems. Carbohydrate Polymers. Elsevier Ltd.; 2011;85(1):1119.

22. Kong L, Ziegler GR. Role of molecular entanglements in starch fiber formation by electrospinning. Biomacromolecules. 2012;13:2247-53.

23. Koski A, Yim K, Shivkumar S. Effect of molecular weight on fibrous PVA produced by electrospinning. Materials Letters. 2004;58(3-4):493-7.

24. McKee MG, Hunley MT, Layman JM, Long TE. Solution rheological behavior and electrospinning of cationic polyelectrolytes. Macromolecules. 2006;39(2):575-83.

25. McKee MG, Wilkes GL, Colby RH, Long TE. Correlations of solution rheology with electrospun fiber formation of linear and branched polyesters. Macromolecules. 2004;37(5):1760-7.

26. Colby RH, Fetters LJ, Funk WG, Graessley WW. Effects of concentration and thermodynamic interaction on the viscoelastic properties of polymer solutions. Macromolecules. 1991;24:3873-82.

27. Rubinstein M, Colby RH. Polymer Physics. Oxford: Oxford University Press; 2003.

28. De Gennes P-G. Scaling Concepts in Polymer Physics. London: Cornell University Press; 1979.

29. Klossner RR, Queen H a, Coughlin AJ, Krause WE. Correlation of chitosan's rheological properties and its ability to electrospin. Biomacromolecules. 2008;9:294753.

30. Zhang W, Chen M, Zha B, Diao G. Correlation of polymer-like solution behaviors with electrospun fiber formation of hydroxypropyl- $\beta$-cyclodextrin and the adsorption study on the fiber. Physical Chemistry Chemical Physics. 2012;14(27):9729-37.

31. Tang C, Saquing CD, Harding JR, Khan S a. In Situ cross-linking of electrospun poly(vinyl alcohol) nanofibers. Macromolecules. 2010;43(2):630-7.

32. Rošic R, Pelipenko J, Kocbek P, Baumgartner S, Bešter-Rogač M, Kristl J. The role of rheology of polymer solutions in predicting nanofiber formation by electrospinning. European Polymer Journal. 2012;48:1374-84.

33. Shenoy SL, Bates WD, Frisch HL, Wnek GE. Role of chain entanglements on fiber formation during electrospinning of polymer solutions: good solvent, non-specific polymer-polymer interaction limit. Polymer. 2005 Apr;46(10):3372-84.

34. Xu X, Yang Q, Wang Y, Yu H, Chen X, Jing X. Biodegradable electrospun poly(llactide) fibers containing antibacterial silver nanoparticles. European Polymer Journal. 2006;42:2081-7. 
35. Yang F, Xu CY, Kotaki M, Wang S, Ramakrishna S. Characterization of neural stem cells on electrospun poly(L-lactic acid) nanofibrous scaffold. Journal of biomaterials science. Polymer edition. 2004;15(12):1483-97.

36. Yang F, Murugan R, Wang S, Ramakrishna S. Electrospinning of nano/micro scale poly(L-lactic acid) aligned fibers and their potential in neural tissue engineering. Biomaterials. 2005 May;26(15):2603-10.

37. Bonadies I, Cimino F, Carfagna C, Pezzella A. Eumelanin 3D Architectures: Electrospun PLA Fiber Templating for Mammalian Pigment Microtube Fabrication. Biomacromolecules. 2015 May 11;16(5):1667-70.

38. Ren J, Liu W, Zhu J, Gu S. Preparation and Characterization of Electrospun, Biodegradable Membranes. Journal of Applied Polymer Science. 2008;109:3390-7.

39. Touny AH, Lawrence JG, Jones AD, Bhaduri SB. Effect of electrospinning parameters on the characterization of PLA/HNT nanocomposite fibers. Journal of Materials Research. 2010 Jan 31;25(05):857-65.

40. Qi Z, Yu H, Chen Y, Zhu M. Highly porous fibers prepared by electrospinning a ternary system of nonsolvent/solvent/poly(l-lactic acid). Materials Letters. Elsevier B.V.; 2009 Feb;63(3-4):415-8.

41. Casasola R, Thomas NL, Trybala A, Georgiadou S. Electrospun poly lactic acid (PLA) fibres: Effect of different solvent systems on fibre morphology and diameter. Polymer. 2014;55(18):4728-37.

42. Smallwood IM. Handbook of organic solvent properties. London: Halsted Press; 1996.

43. Barton AFM. Handbook of solubility parameters. 2nd ed. Boca Raton, Fla.; London : CRC Press; 1983. p. 142-55.

44. Agrawal A, Saran AD, Rath SS, Khanna A. Constrained nonlinear optimization for solubility parameters of poly(lactic acid) and poly(glycolic acid)—validation and comparison. Polymer. 2004;45(25):8603-12.

45. Weast RC. Handbook of Physics an Chemistry. 54th ed. Weast RC, editor. Cleveland: CRC Press; 1974.

46. Jarusuwannapoom T, Hongrojjanawiwat W, Jitjaicham S, Wannatong L, Nithitanakul M, Pattamaprom C, et al. Effect of solvents on electro-spinnability of polystyrene solutions and morphological appearance of resulting electrospun polystyrene fibers. European Polymer Journal. 2005;41(3):409-21.

47. Van der Schueren L, De Schoenmaker B, Kalaoglu ÖI, De Clerck K. An alternative solvent system for the steady state electrospinning of polycaprolactone. European Polymer Journal. Elsevier Ltd; 2011 Jun;47(6):1256-63. 
48. Sun Z, Deitzel JM, Knopf J, Chen X, Gillespie JW. The effect of solvent dielectric properties on the collection of oriented electrospun fibers. Journal of Applied Polymer Science. 2012;125(4):2585-94.

49. Mit-uppatham C, Nithitanakul M, Supaphol P. Ultrafine electrospun polyamide-6 fibers: effect of solution conditions on morphology and average fiber diameter. Macromolecular Chemistry and Physics. 2004 Nov 26;205(17):2327-38.

50. Wang C, Chien HS, Yan KW, Hung CL, Hung KL, Tsai SJ, et al. Correlation between processing parameters and microstructure of electrospun poly(D,l-lactic acid) nanofibers. Polymer. 2009;50(25):6100-10.

51. Tanford Charles. Physical Chemistry of Macromolecules. London: John Wiley \& Sons, Inc., New York; 1961.

52. Stevens Malcom P. Polymer Chemistry: An Introduction. New York: Oxford University Press; 1190. 